\title{
Phenotyping the Function of TRPV1-Expressing Sensory Neurons by Targeted Axonal Silencing
}

\author{
Christian Brenneis, ${ }^{1,2}$ Katrin Kistner, ${ }^{3}$ Michelino Puopolo, ${ }^{4}$ David Segal, ${ }^{1}$ David Roberson, ${ }^{1}$ Marco Sisignano, ${ }^{2}$ \\ Sandra Labocha, ${ }^{2}$ Nerea Ferreirós, ${ }^{2}$ Amanda Strominger, ${ }^{1}$ Enrique J. Cobos, ${ }^{1}$ Nader Ghasemlou, ${ }^{1}$ Gerd Geisslinger, ${ }^{2}$ \\ Peter W. Reeh, ${ }^{3}$ Bruce P. Bean, ${ }^{4}$ and Clifford J. Woolf ${ }^{1,4}$ \\ ${ }^{1}$ F.M. Kirby Neurobiology Center, Children's Hospital Boston, Boston, Massachusetts 02115, ${ }^{2}$ Institute of Clinical Pharmacology, Pharmazentrum \\ Frankfurt/Zentrum für Arzneimittelforschung, Entwicklung und Sicherheit (ZAFES), University Hospital, Goethe-University, D-60590 Frankfurt am Main, \\ Germany, ${ }^{3}$ Department of Physiology and Pathophysiology, Friedrich-Alexander-University Erlangen-Nürnberg, D-91054 Erlangen, Germany, and \\ ${ }^{4}$ Department of Neurobiology, Harvard Medical School, Boston, Massachusetts 02115
}

Specific somatosensations may be processed by different subsets of primary afferents. C-fibers expressing heat-sensitive TRPV1 channels are proposed, for example, to be heat but not mechanical pain detectors. To phenotype in rats the sensory function of TRPV1 ${ }^{+}$ afferents, we rapidly and selectively silenced only their activity, by introducing the membrane-impermeant sodium channel blocker QX-314 into these axons via the TRPV1 channel pore. Using tandem mass spectrometry we show that upon activation with capsaicin, QX-314 selectively accumulates in the cytosol only of TRPV1-expressing cells, and not in control cells. Exposure to QX-314 and capsaicin induces in small DRG neurons a robust sodium current block within $30 \mathrm{~s}$. In sciatic nerves, application of extracellular QX-314 with capsaicin persistently reduces $\mathrm{C}$-fiber but not A-fiber compound action potentials and this effect does not occur in TRPV1 ${ }^{-1-}$ mice. Behavioral phenotyping after selectively silencing $\mathrm{TRPV} 1^{+}$sciatic nerve axons by perineural injections of QX-314 and capsaicin reveals deficits in heat and mechanical pressure but not pinprick or light touch perception. The response to intraplantar capsaicin is substantially reduced, as expected. During inflammation, silencing TRPV1 ${ }^{+}$axons abolishes heat, mechanical, and cold hyperalgesia but tactile and cold allodynia remain following peripheral nerve injury. These results indicate that TRPV1-expressing sensory neurons process particular thermal and mechanical somatosensations, and that the sensory channels activated by mechanical and cold stimuli to produce pain in naive/inflamed rats differ from those in animals after peripheral nerve injury.

\section{Introduction}

Noxious temperature, mechanical, or chemical stimuli to the skin are processed by defined subsets of high-threshold primary sensory neurons called nociceptors (noxious stimulus detectors), which have free nerve endings in the skin and project to neurons in the dorsal horn of the spinal cord (Woolf and Ma, 2007; Bráz and Basbaum, 2009; Latremoliere and Woolf, 2009). Nociceptors

Received June 12, 2012; revised 0ct. 9, 2012; accepted Nov. 8, 2012.

Author contributions: C.B.,P.W.R., B.P.B., and C.J.W. designed research;C.B., K.K., M.P., D.S., D.R., M.S., S.L., N.F., A.S., E.J.C., and N.G. performed research; G.G. contributed unpublished reagents/analytic tools; C.B., K.K., M.P., and E.J.C. analyzed data; C.B. and C.J.W. wrote the paper.

This work was supported by the National Institutes of Health (NS072040 to C.J.W. and B.P.B.) (NS064274 to B.P.B.), by the Deutsche Forschungsgemeinschaft (BR 2923/1-1 to C.B. and GE 695 to G.G.), and by LOEWE (LandesOffensive zur Entwicklung Wissenschaftlich-Ökonomischer Exzellenz) Lipid Signaling Forschungszentrum Frankfurt (LiFF). K.K. and P.W.R. were supported by the Else Kröner-Fresenius-Stiftung and the Johannes und Frieda-MarohnStiftung. E.J.C. was funded by the Ministerio de Ciencia e Innovacion (MICINN)/Fulbright program, and by the Research Program of the University of Granada. This work was also supported by a sponsored research agreement with Endo Pharmaceuticals to C.J.W. and B.P.B.

Endo Pharmaceuticals has licensed technology for silencing fibers from Harvard University invented by B.B. and C.J.W.

Correspondence should be addressed to Dr. Clifford J. Woolf, F.M. Kirby Neurobiology Center, Children's Hospital Boston, Boston, MA 02115. E-mail: Clifford.Woolf@childrens.harvard.edu.

M. Puopolo's present address: Department of Anesthesiology, Stony Brook Medicine, Stony Brook, NY 11794.

E.J. Cobos' present address: Department of Pharmacology and Neurosciences Institute. University of Granada, Granada 18012, Spain

DOI:10.1523/JNEUROSCI.2804-12.2013

Copyright $\odot 2013$ the authors $\quad 0270-6474 / 13 / 330315-12 \$ 15.00 / 0$ can be anatomically segregated into the much more numerous slowly conducting, nonmyelinated $\mathrm{C}$-fiber and the fasterconducting, thinly myelinated $\mathrm{A} \delta$-fiber neurons. C-fiber neurons typically are polymodal, and chemical, heat, cold, or mechanical stimulation activate overlapping populations, presumably reflecting coexpression of transducers sensitive to these different stimuli (Woolf and Ma, 2007). The best-characterized sensory transducers are those for temperature and are encoded by the transient receptor potential (TRP)-channel gene family (Caterina et al., 2000; Wang and Woolf, 2005; Clapham, 2007). TRPV1 is activated by noxious hot $\left(>42^{\circ} \mathrm{C}\right)$ temperatures whole TRPM8 is activated by $\operatorname{cool}\left(<26^{\circ} \mathrm{C}\right)$ temperatures. These channels are predominantly expressed by different sensory neuronal populations (Caterina et al., 2000; Bautista et al., 2007). Hence, a classification of neuronal coding by virtue of the TRPchannel isoforms they express seems plausible.

What remains uncertain, though, is exactly how different nociceptor subtypes with complex receptive field properties contribute to specific pain qualities in vivo. The labeled line hypothesis of sensory processing proposes, for example, that there are separate neural pathways mediated by distinct sensory neurons for heat, cold, or mechanical stimuli.

In mice, the sensory coding carried by TRPV ${ }^{+}$neurons has been investigated by two different strategies. In the first, TRPV1expressing terminals in the dorsal horn were ablated by intrathe- 
cal injection of capsaicin. In the second, TRPV1-expressing neurons were killed by diphtheria toxin expressed under control of the TRPV1 promoter (Cavanaugh et al., 2009; Scherrer et al., 2009; Mishra et al., 2010). Both strategies abolished the ability to detect noxious hot or cold stimuli while touch and mechanical pain sensation remained intact. In contrast, the genetic ablation of unmyelinated sensory neurons expressing Mrgprd (Masrelated G-protein-coupled receptor D) G-protein-coupled receptors reduces behavioral sensitivity to noxious mechanical stimuli but not to heat or cold pain (Cavanaugh et al., 2009). During carrageenan-induced paw inflammation or after sciatic nerve ligation, deletion of TRPV $1^{+}$nociceptors also did not impair mechanosensitivity (Mishra et al., 2010).

All of these strategies have the complication that the effects are investigated days after the manipulation, which raises the possibility that they may reflect, in part, relatively long-term changes in a signaling system known to be highly plastic. An alternative strategy to determine the function of defined sets of afferents that can be implemented much more rapidly is to produce a temporary blockade of neuronal activity by introducing the charged sodium channel blocker QX-314 into axons via the TRPV1 channel pore (Binshtok et al., 2007). We have now validated and used this strategy to establish the sensory deficits that result after selectively silencing TRPV $1^{+}$axons in naive, inflamed, and neuropathic rats.

\section{Materials and Methods}

Animals

Eight-to-ten-week-old male Sprague Dawley rats (200-250 g) (Charles River Laboratories) were used. All animal procedures were approved by the Institutional Animal Care and Use Committee of Children's Hospital Boston. All tests were performed by an experimenter blinded to treatment. Both male and female (25-30 g) inbred C57BL 6 mice were used, the TRPV1 KO strain was based on a generous gift from J. B. Davis (Davis et al., 2000). All procedures were approved by the animal protection authorities (local district government, Ansbach, Germany).

\section{Perisciatic injections}

We studied the effects of QX-314 (lidocaine N-ethyl bromide, SigmaAldrich), and its combination with capsaicin (Sigma-Aldrich), in naive animals and in animals during chronic pain (inflammatory and neuropathic pain). Groups of 6-9 rats were lightly anesthetized by inhalation of $2 \%$ isoflurane and injected with $0.2 \mathrm{ml}$ of $0.5 \%$ QX-314 or with its solvent (saline) into the left sciatic notch behind the hip bone. Ten minutes later, the rats were anesthetized again and received an injection of $0.05 \%$ capsaicin or its vehicle (10\% EtOH and 5\% Tween 80$)$ at the same site. Lidocaine $2 \%$ (Sigma-Aldrich) was injected in a separate group of rats.

\section{Models of chronic pain and behavioral phenotyping}

To induce peripheral inflammation, rats were intraplantarly injected with $100 \mu$ l of complete Freund's adjuvant (CFA; Sigma-Aldrich), using a 1710 TLL Hamilton microsyringe (Hamilton) with a 301/2-gauge needle. Inflammation of the paw in the rat peaks at $48 \mathrm{~h}$ and is associated with hypersensitivity to thermal and mechanical stimuli (Jasmin et al., 1998; Ji et al., 2002; Allchorne et al., 2005). Therefore, the effects of QX-314, capsaicin, and their combination were tested $48 \mathrm{~h}$ after the induction of peripheral inflammation. To induce peripheral neuropathy, we used the spared nerve injury (SNI) model of peripheral neuropathic pain. Briefly, two of the three terminal distal branches of the sciatic nerve (the common peroneal and the tibial nerves) were ligated with silk (5-0) and distally transected, leaving the third branch (the sural nerve) intact, as previously described (Decosterd and Woolf, 2000). The effects of QX314 , capsaicin, or their combination were tested $8 \mathrm{~d}$ after nerve injury, when tactile and cold allodynia are fully established (Decosterd and Woolf, 2000). Surgery and CFA administration was performed under 3\% isoflurane anesthesia.

\section{Behavioral assays}

Mechanical stimulation. All mechanical tests were performed in animals placed in individual test compartments in an elevated mesh-bottomed platform with a grid (to provide access to the ventral side of the hindpaws). Animals were habituated to the evaluation chambers during 90 min in two different sessions separated for at least $1 \mathrm{~d}$ before starting the evaluations. The day of the evaluation, rats were habituated for 60 additional minutes before the beginning of the tests. Mechanical thresholds were assessed by using a blunt or a punctate stimulation (Pinch and von Frey tests, respectively). The pinch test was performed using a Rodent Pincher Analgesia Meter (Bioseb) (Roberson et al., 2011). Briefly, an increasing force was applied with a calibrated forceps to the lateral side of the left hindpaw (sensory field of the sciatic nerve) and the force needed to induce vocalization or rapid paw withdrawal was determined (LuisDelgado et al., 2006). A cutoff force of $400 \mathrm{~g}$ was used in all evaluations. To determine mechanical thresholds to a punctate stimulation, the von Frey Test was used (Decosterd and Woolf, 2000). The rats were first stimulated with a $8 \mathrm{~g}$ filament for $5 \mathrm{~s}$. A positive response was counted as five responses out of 10 stimuli. Each rat was then tested with higher or lower pressure filaments depending on whether they showed a positive or negative response. This was repeated until either the rat showed a response, in the case of increasing force, or until the rat did not show a response, in the case of decreasing force. The value of the lowest filament needed to induce a positive response was defined as the von Frey threshold.

In addition to the assessment of mechanical thresholds, we used two additional types of mechanical stimuli-a punctate painful stimulation (pinprick test), and a light innocuous stimulation (stimulation using a soft paint brush)— to determine whether the combination of QX-314 and capsaicin could interfere in the responses to a clearly painful or innocuous stimulation. Pinprick was assessed using an Austerlitz insect pin (size, 000; Fine Science Tools). This pin was gently applied to the lateral plantar surface of the paw without moving the paw or penetrating the skin. Responses were identified by a rapid paw withdrawal immediately after stimulation. To investigate responses to an innocuous mechanical stimulus, animals were gently stroked in the lateral plantar surface of the paw with a soft paint brush (series, 222; size, 0; Winsor \& Newton Cotman). The average number of responses (paw movements) induced by five brush stimuli repeated every $5 \mathrm{~min}$ was calculated. The procedure was repeated three times with an interval of $10 \mathrm{~min}$ between each set. Due to the rapid habituation of the rats to the brush stimulus, baseline measurements were not performed.

Thermal nociception (Hargreaves test). Rats were habituated for $30 \mathrm{~min}$ in two sessions separated for at least $1 \mathrm{~d}$, to individual Plexiglas chambers placed on a glass floor. The day of the evaluation, animals were habituated for 15 additional minutes before the beginning of the test. After habituation, a beam of radiant heat was focused to the plantar surface of the left hindpaw using a plantar test device (Ugo Basile) (Hargreaves et al., 1988; Binshtok et al., 2007, 2009). The intensity of the light was adjusted at the start of the experiments such that averaged baseline latencies were $\sim 15 \mathrm{~s}$. Cutoff time was set to $24 \mathrm{~s}$.

Cold stimulation. To test the effect of QX-314, capsaicin, and their combination on cold hyperalgesia in CFA-treated rats, animals were habituated to a Peltier-cooled cold plate set to $20^{\circ} \mathrm{C}$. One hour after perineural injections, rats were placed on the plate at $5^{\circ} \mathrm{C}$ and the number of flinches determined over $5 \mathrm{~min}$, as previously described (Allchorne et al., 2005). To test for cold allodynia during neuropathy, a drop of acetone was applied to the lateral plantar side of the paw inducing evaporative cooling and scored as follows: 0 , no response (sniffing or walking was not considered nociceptive); 1, 1 flinch; 2, 2-4 flinches; $3,>4$ flinches and or licking/biting. Three stimulations were made per time point and the average calculated.

Motor function. To assess motor function after perineural treatments, the movement of the toes was evaluated. Rats were covered with a cloth and gently lifted by the tail, uncovering the hindpaws for clear observation. Under this condition the digits normally spread. The response was scored as follows: 0 , no spreading; 1 , intermediate spreading; 2 , full spreading. Full spreading was defined as a complete, wide, and sustained 
(at least $2 \mathrm{~s}$ ) spreading of all toes. The affected paw was only scored when full toe spreading was observed on the contralateral side.

Capsaicin-evoked behaviors. Rats were habituated to evaluation chambers for $60 \mathrm{~min}$ at a time on 3 different days before beginning behavioral testing. On the day of evaluation, two sequential perisciatic injections were performed as previously described. Rats were returned to their home cages for $30 \mathrm{~min}$ after the second perisciatic injection, then transferred to the evaluation chambers for an additional $30 \mathrm{~min}$ before administration of lateral plantar injections. Capsaicin $(0.005 \%, 20 \mu \mathrm{l})$ was injected intradermally into the lateral plantar surface of the left hindpaw at the interface of hairy and glabrous skin. Immediately after lateral plantar injection, rats were returned to evaluation chambers and behavioral responses were recorded by video camera placed below the chambers. Video analysis of voluntary behavioral responses to intradermal capsaicin administration was performed by a blinded observer for $15 \mathrm{~min}$ after capsaicin injection. Nocifensive leg lifts were defined as spontaneous lifting of the paw not contiguous with animal locomotion or body repositioning. Licking time was determined by quantifying the total duration of all licking bouts directed at the left hindpaw.

\section{QX-314 cellular uptake assay}

Chinese hamster ovarian $(\mathrm{CHO})$ cells stably transfected with a plasmid encoding for full-length rat TRPV1 in pcDNA3.1 or control pcDNA3.1 (Sándor et al., 2005) (both generous gifts from Zoltan Sándor of the Department of Pharmacology and Pharmacotherapy at the University of Pécs, Hungary) were plated on six-well dishes coated with poly-D-lysine $(0.5 \mathrm{mg} / \mathrm{ml}$, Sigma-Aldrich). When cells reached confluence, they were incubated with $1 \mu \mathrm{M}$ capsaicin and QX-314 at different concentrations for $10 \mathrm{~min}$. After washing cells with $2 \mathrm{ml}$ of PBS (4 times), $500 \mu \mathrm{l}$ of $0.1 \mathrm{M}$ $\mathrm{HCl}$ containing $1 \%$ Triton X100 was added and cells incubated for $5 \mathrm{~min}$ for cell lysis. The lysate was centrifuged at $10,000 \times g$ and the supernatant analyzed by liquid chromatography-electrospray ionization-tandem mass spectrometry (LC-MS/MS). To differentiate between QX-314 accumulation in the cytosolic and membrane fractions of human TRPV1 (hTRPV1), inducible HEK-293 (generous gift from David Julius, University of California, San Francisco) cells were grown on $10 \mathrm{~cm}$ plastic dishes and induced with $10 \mathrm{~nm}$ doxycyclin. Next day, cells were incubated with $0.5 \mathrm{~mm}$ QX-314 and $1 \mu \mathrm{M}$ capsaicin for drug uptake studies as described above. Washed cells were then trypsinized (here not lysed), centrifuged for $5 \mathrm{~min}$ at $134 \times \mathrm{g}$, and the cell pellet washed again with PBS. Then, the cells were resuspended in $500 \mu \mathrm{l}$ of PBS, transferred to glass ultracentrifugation tubes (Beckman), and centrifuged for $1 \mathrm{~h}$ at $120.000 \times \mathrm{g}$. QX-314 was measured by LC-MS/MS from the supernatant or the washed membrane pellet, which was resuspended in $500 \mu$ l of lysis buffer.

Time course studies for QX-314 release were done with hTRPV1inducible HEK-293 cells growing on 12-well plates. After incubation with $0.5 \mathrm{~mm}$ QX-314 and $1 \mu \mathrm{M}$ capsaicin for $10 \mathrm{~min}$, cells were washed four times with PBS and incubated in fresh culture medium [DMEM, 10\% FCS, penicillin/streptomycin $(\mathrm{P} / \mathrm{S})]$. At different time points, the medium $(1 \mathrm{ml})$ was taken and the cells were washed $(4 \times)$ and lysed in $300 \mu \mathrm{l}$ of $0.1 \mathrm{M} \mathrm{HCl}$ containing $1 \%$ TritonX100. QX-314 was then investigated in the culture medium and cell lysate by LC-MS/MS from the same cells.

\section{LC-MS/MS analysis of QX-314}

Instrumentation. Sample analysis was performed by using LC-MS/MS. The LC equipment consisted of an Agilent 1200 Series binary pump and degasser connected to an HTC PAL autosampler (Chromtech). A triple quadrupole mass spectrometer 5500 QTRAP equipped with a Turbo V IonSpraySource operating in positive electrospray ionization mode was used for detection (AB Sciex). High-purity nitrogen for the mass spectrometer was produced by the nitrogen generator NGM 22-LC/MS (CMC Instruments).

Chromatographic conditions. Chromatographic separations were obtained under gradient conditions using a Synergi Fusion-RP column (inner diameter, $150 \times 2 \mathrm{~mm}$; particle size, $4 \mu \mathrm{m}$; pore size, $80 \AA$ ) (Phenomenex). The mobile phase consisted of $10 \mathrm{~mm}$ ammonium acetate (A) and acetonitrile (B). The gradient was as follows: from $t=0$ to $1 \mathrm{~min}$, $90 \% \mathrm{~A}$; followed from $t=1$ to $2.5 \mathrm{~min}$ by a linear gradient from 90 to
$50 \% \mathrm{~A}$; then from $t=2.5$ to $3 \mathrm{~min}, 50 \% \mathrm{~A}$; from $t=3$ to $3.5 \mathrm{~min}$ a linear gradient from 50 to $5 \% \mathrm{~A}$; which was maintained for $1.5 \mathrm{~min}$ and in the next $1.5 \mathrm{~min}$ increased to $90 \% \mathrm{~A}$. These conditions were maintained for $5.5 \mathrm{~min}$ to re-equilibrate the system. Ten microliters of the extracted samples were injected into the LC electrospray ionization MS/MS. The flow rate was set at $0.45 \mathrm{ml} / \mathrm{min}$. The mass spectrometer was operated in positive ion mode. Precursor-to-product ion transitions of mass-tocharge ratio $(\mathrm{m} / \mathrm{z}) 264.1 \rightarrow 86.0$ for QX-314 (collision energy, $31 \mathrm{~V}$ ) and $\mathrm{m} / \mathrm{z} 221.1 \rightarrow 86.1$ for the internal standard (IS) prilocain (19 V) were used as quantifier for the multiple reaction monitoring. All quadrupoles were working at unit resolution. Integration was performed with Analyst Software V1.5 (AB Sciex).

Standard calibration. A calibration curve from 1 to $1000 \mathrm{ng} / \mathrm{ml}$ QX-314 was prepared by spiking $50 \mu \mathrm{l}$ of the appropriate aqueous working solutions of the analyte in the lysis buffer.

Sample preparation. Fifty microliters of the samples were spiked with $50 \mu \mathrm{l}$ of a solution containing the internal standard (IS) in methanol (100 $\mathrm{ng} / \mathrm{ml}$ ), $900 \mu \mathrm{l}$ of water added, and samples vortexed for $1 \mathrm{~min}$, centrifuged at 15,000 rpm $(17,000 \times g)$, transferred to the HPLC vials and injected in the chromatographic system. The temperature of the sample compartment of the autosampler was set at $6^{\circ} \mathrm{C}$.

\section{Voltage clamp of rat DRG neurons}

Preparation of rat DRG neurons.. Dissociated neurons were prepared from DRGs taken from thoracic and lumbar regions of Sprague Dawley rats ( postnatal day 20-31) after anesthesia with isoflurane. After dissection in cold $\mathrm{Ca}^{2+}, \mathrm{Mg}^{2+}$-free Hank's solution ( $137 \mathrm{~mm} \mathrm{NaCl}, 5.3 \mathrm{~mm}$ $\mathrm{KCl}, 0.33 \mathrm{~mm} \mathrm{Na}_{2} \mathrm{HPO}_{4}, 0.44 \mathrm{~mm} \mathrm{KH}_{2} \mathrm{PO}_{4}, 5.5 \mathrm{~mm}$ glucose, $5 \mathrm{~mm}$ HEPES, pH 7.4 with $\mathrm{NaOH}$ ), ganglia were chopped in half and incubated for $20 \mathrm{~min}$ at $34^{\circ} \mathrm{C}$ in $\mathrm{Ca}^{2+}, \mathrm{Mg}^{2+}$-free Hank's solution containing 20 $\mathrm{U} / \mathrm{ml}$ papain (Worthington Biochemical) with $5 \mathrm{~mm}$ DL-cysteine. Ganglia were then washed and incubated for $20 \mathrm{~min}$ at $34^{\circ} \mathrm{C}$ in $\mathrm{Ca}^{2+}, \mathrm{Mg}^{2+}$-free Hank's solution containing $3 \mathrm{mg} / \mathrm{ml}$ collagenase (type I, Sigma-Aldrich) and $4 \mathrm{mg} / \mathrm{ml}$ Dispase II (Boehringer Mannheim), and then placed in Leibovitz's L-15 medium (Invitrogen) supplemented with 10\% fetal calf serum, $5 \mathrm{~mm}$ HEPES, and $50 \mathrm{ng} / \mathrm{ml}$ NGF (Invitrogen). Cells were dispersed by mechanical trituration using a fire-polished Pasteur pipette, plated on glass coverslips treated with $50 \mu \mathrm{g} / \mathrm{ml}$ poly-D-lysine, incubated in the supplemented $\mathrm{L}-15$ solution at $34^{\circ} \mathrm{C}$ (in $5 \% \mathrm{CO}_{2}$ ) for $2-3 \mathrm{~h}$, then stored at $4^{\circ} \mathrm{C}$ in Neurobasal medium (Invitrogen) and used the next day. This protocol yields spherical cell bodies without neurites, which can be lifted from the coverslip after establishing the whole-cell recording to facilitate rapid solution changes using flow pipes.

Experiments measuring the effect of external QX-314. Recordings were made from small diameter $(18-30 \mu \mathrm{m})$ DRG neurons, of which $\sim 80 \%$ responded to capsaicin. Whole-cell recordings were made with a Multiclamp 700B amplifier (Molecular Devices) using patch pipettes pulled from thin-walled borosilicate glass $(100 \mu \mathrm{l}$ microcapillaries, VWR International) to have a resistance of $1.8-2.5 \mathrm{M} \Omega$ when filled with the standard internal solution containing $110 \mathrm{~mm} \mathrm{CsCl}, 13 \mathrm{~mm} \mathrm{CsF}, 9 \mathrm{~mm} \mathrm{NaCl}$, $1.8 \mathrm{~mm} \mathrm{MgCl}_{2}, 9 \mathrm{~mm}$ EGTA, $14 \mathrm{~mm}$ phosphocreatine (Tris salt), $4 \mathrm{~mm}$ MgATP, 0.3 mm GTP (Tris salt), 9 mM HEPES, pH adjusted to 7.2 with $\sim 25 \mathrm{~mm}$ CsOH. Pipettes were wrapped with Parafilm to reduce pipette capacitance. After the whole-cell configuration was established, the cell was lifted off in front of an array of quartz capillary tubes (internal diameter, $250 \mu \mathrm{m}$ ) that allowed fast change of external solutions. In whole-cell mode, the series resistance was measured (typically 3-8 M $\Omega$ ) and was compensated $70-80 \%$. Currents were filtered at $10 \mathrm{kHz}$ and digitized at $20 \mathrm{kHz}$ using a Digidata $1321 \mathrm{~A}$ interface controlled by pClamp 9 software (Molecular Devices). Experiments were done at room temperature.

Sodium current was activated by $50 \mathrm{~ms}$ steps from -80 to $0 \mathrm{mV}$, delivered every second; the step to $0 \mathrm{mV}$ was followed by two $120 \mathrm{~ms}$ ramps between -160 and $+100 \mathrm{mV}$ ( 1 in each direction) to measure the current-voltage relation of TRPV1 current. The extracellular solution was $151 \mathrm{~mm} \mathrm{NaCl}, 2.5 \mathrm{~mm} \mathrm{KCl}, 2 \mathrm{~mm} \mathrm{BaCl}{ }_{2}, 1 \mathrm{~mm} \mathrm{MgCl}_{2}, 10 \mathrm{~mm}$ HEPES, $13 \mathrm{~mm}$ glucose, pH 7.4 with $\mathrm{NaOH}$, with $30 \mathrm{~mm} \mathrm{CdCl}_{2}$ to block calcium channel currents. In experiments with external QX-314 and capsaicin, solutions were changed using rapid movement $(<1 \mathrm{~s})$ of the cell between 
flow pipes. Ten millimole QX-314 (bromide salt, Sigma-Aldrich) and $1 \mu \mathrm{M}$ capsaicin (Sigma-Aldrich) were applied together for $10 \mathrm{~s}$ every $50 \mathrm{~s}$. The $40 \mathrm{~s}$ wash-out period allowed recovery of the TRPV1-evoked current so that sodium current could be measured without the background of the TRPV1 current. Experiments were restricted to neurons in which TRPV1 current evoked by $1 \mu \mathrm{M}$ capsaicin was at least $10 \mathrm{nA}$ measured at $+80 \mathrm{mV}$ (corresponding to $\sim-2 \mathrm{nA}$ at $-80 \mathrm{mV}$ ). Control experiments were done on separate neurons using the same protocol but applying only 10 mM QX-314 or only $1 \mu \mathrm{M}$ capsaicin. Data are reported as mean \pm SD with $n=5-7$ neurons for each condition.

Experiments measuring the effect of internal QX-314. Experiments using internal solutions with various concentrations of QX-314 were studied on the same day as solutions without QX-314 so that the same populations of cells were sampled. Sodium currents were evoked with the command protocol delivered continuously every second starting at $\sim 2$ min after the cell was first dialyzed (following the time taken to lift the cells in front of flow pipes and to measure and adjust the series resistance compensation). The effect of QX-314 was quantified as the reduction of the current measured after 10 min of continuous stimulation ( $\sim 12$ min of dialysis) compared with the current in response to the second stimulating pulse (after $\sim 2$ min of dialysis); the $\sim 25 \%$ decline in sodium current under control conditions represents partly a small degree of rundown of sodium currents but mainly a small degree of cumulative use-dependent decline of sodium current present even under control conditions. In experiments with intracellular QX-314, the tip of the pipettes was filled with a small amount of QX-314-free solution to delay the dialysis of the cells to allow time for adjusting series resistance compensation. Even so, with either 50 or $100 \mu \mathrm{M}$ QX-314, sodium currents declined very rapidly immediately after stimulation started after 2 min of dialysis, suggesting that channels had already seen some QX-314 by the time the reference currents were recorded. This would result in an underestimate of the blocking effect of QX-314.

Compound action potential recordings from $C$-fibers and A-fibers of isolated mouse sciatic nerves

Compound action potential (CAP) recordings were made from C-fibers and A-fibers of isolated mouse sciatic nerves (Bremer et al., 2011). Nerves from C57BL 16 or TRPV1 ${ }^{-1-}$ mice, killed in pure $\mathrm{CO}_{2}$ atmosphere, were exposed and excised from where they emerge out of the lumbar plexus to the trifurcation into tibial, sural, and peroneal nerves. The nerve was mounted in a three-compartment chamber and continuously superfused with synthetic interstitial fluid (SIF) (Bretag, 1969) containing (in mM) $108 \mathrm{NaCl}, 3.48 \mathrm{KCl}, 3.5 \mathrm{MgSO}_{4}, 26 \mathrm{NaHCO}_{3}, 1.7 \mathrm{NaH}_{2} \mathrm{PO}_{4}, 1.5 \mathrm{CaCl}_{2}$, 9.6 sodium gluconate, 5.5 glucose, and 7.6 sucrose or different test solutions, respectively, at a rate of $5-7 \mathrm{ml} / \mathrm{min}$. PH was maintained at 7.4 by bubbling with carbogen ( $95 \%$ oxygen and $5 \%$ carbon dioxide) and temperature was held constant at $37^{\circ} \mathrm{C}$. Each end of the nerve was threaded into one of two chambers filled with fluorocarbon oil FC-43 and placed on gold wire electrodes. One chamber contained the recording electrodes while the other was used for electrical stimulation. To monitor the entire population of sciatic nerve axons activated by electrical stimulation, the CAP responses were evoked by $25 \%$ supramaximal electrical stimulation with constant voltage pulses (A395, WPI) of fixed duration $(0.1 \mathrm{~ms})$ at a rate of one every $20 \mathrm{~s}$ and responses were recorded monopolarly. After a
B cytosolic fraction (500 $\mu \mathrm{M} Q \mathrm{QX}-314)$
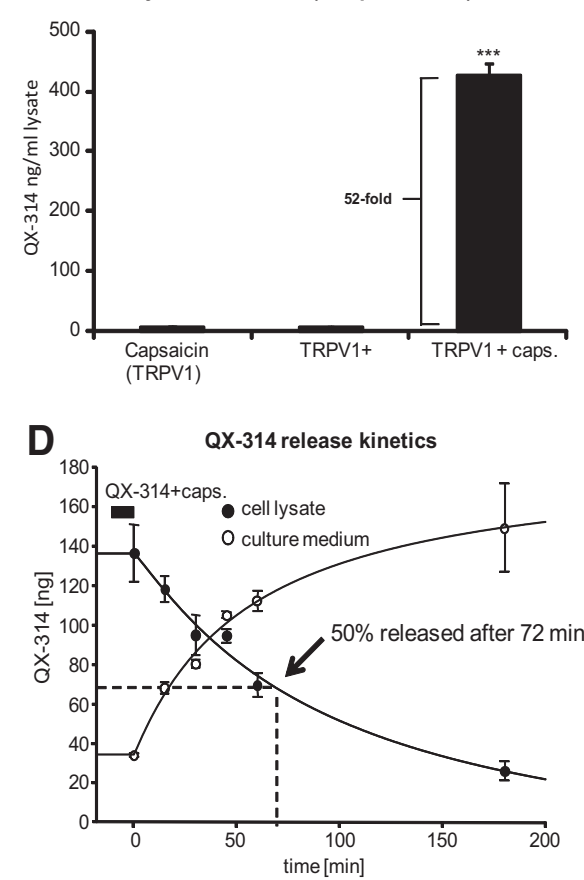

Figure 1. QX-314 accumulates selectively in TRPV1-expressing cells upon capsaicin stimulation. $\boldsymbol{A}$, Concentration-response (

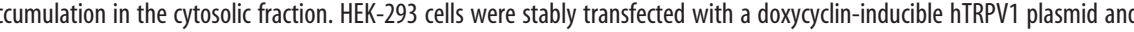
cellure medium $(1 \mathrm{ml})$ or in cell lysates $(300 \mu \mathrm{M})(n=3)$. Data represent the average of the absolute drug amount in both solutions \pm SEM. Significance was calculated by two-way ANOVA and Bonferroni correction. ${ }^{*} p<0.05$, ${ }^{* *} p<0.01$, ${ }^{* * *} p<$ 0.001 compared with cells expressing no TRPV1.

20 min control period in SIF, the effects of the test substances applied for 5-10 min on both latency as well as amplitude of C-fiber and A-fiber CAPs were assessed. Amplitude was taken as the difference between the maximum and minimum excursions of the recorded waveform (peak to peak). Latency was the second parameter monitored and assessed as the time at which a trigger level in the lower third of the CAP up-stroke was exceeded. On A-fiber CAPs, an additional preanalyzing exponential fit was performed to eliminate the inevitable but steady rundown and to discriminate it from respective test substance effects. Data were acquired and analyzed using a CED Micro1401 and Spike2 software (Cambridge Electronic Design).

\section{Statistics}

Statistical differences in cell culture experiments were analyzed by twoway ANOVA and Bonferroni correction using Sigmastat software. CAPs were analyzed using Wilcoxon matched pairs test for intraindividual $\left({ }^{\star}\right)$ or Mann-Whitney $U$ test for group (\#) comparisons with Statistika 7 software (StatSoft). Temporal courses from animal behavior data were analyzed by two-way repeated-measures ANOVA, followed by post hoc Bonferroni analysis using Sigmastat software. Differences were considered significant at $p<0.05$.

\section{Results}

\section{Permeation of QX-314 into cells via TRPV1 channels}

We have previously demonstrated that it is possible to selectively block sodium currents and action potentials in TRPV1expressing DRG sensory neurons by coadministering extracellular QX-314 and capsaicin, with each compound by itself having 


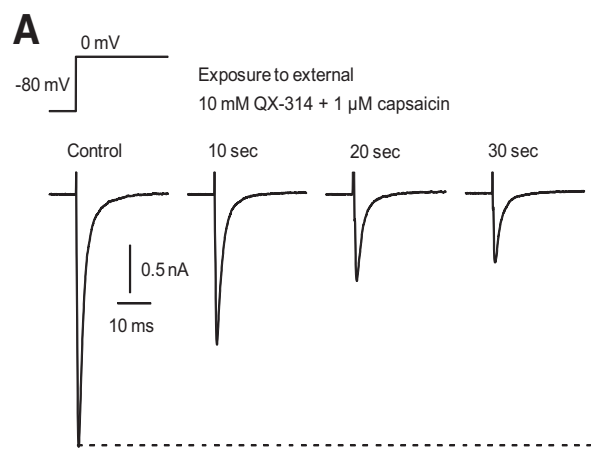

\section{B}

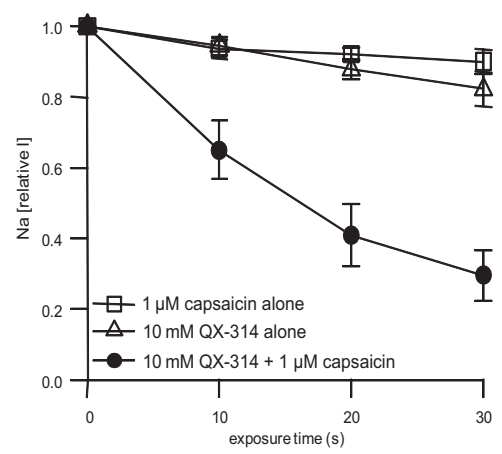

C

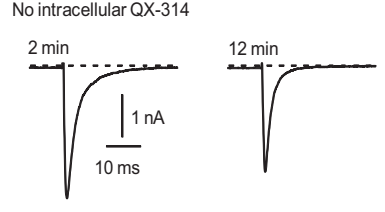

$100 \mu \mathrm{M}$ intracellular QX-314

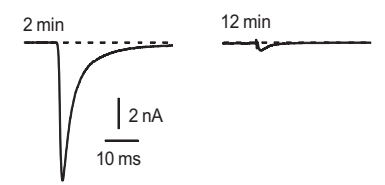

D

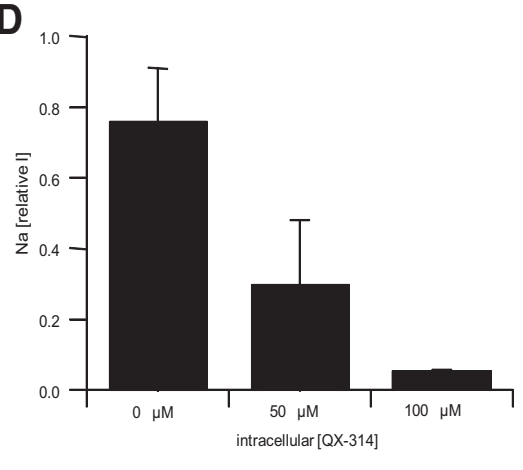

Figure 2. Time course of sodium channel inhibition in DRG neurons by QX-314 following entry through TRPV1 channels and by internal application of QX-314. A, Time course of sodium channel inhibition by QX-314 and capsaicin applied externally to voltageclamped rat DRG neurons. Sodium current was elicited by a voltage step from -80 to $0 \mathrm{mV}$ delivered every second. Ten millimole QX-314 and $1 \mu \mathrm{m}$ capsaicin were coapplied for multiple 10 s periods, each exposure period separated by $40 \mathrm{~s}$ of washing by control solution to reverse the capsaicin-activated TRPV1 current. $\boldsymbol{B}$, Combined results for the experiment in $\boldsymbol{A}$ performed in five DRG neurons (solid circles). In addition, the same protocol was performed applying either $1 \mu \mathrm{m}$ capsaicin alone $(n=7)$ or $10 \mathrm{~mm}$ QX-314 alone $(n=7)$, showing that both must be present for substantial inhibition of sodium channels. C, Block of sodium current by QX-314 added to the intracellular (pipette) solution in whole-cell recording from voltage-clamped DRG neurons. Upper traces, Sodium currents elicited by a step from -80 to $0 \mathrm{mV}$ recorded after $2 \mathrm{~min}$ and $12 \mathrm{~min}$ in a cell dialyzed by the control intracellular solution. Bottom traces, Same in a cell dialyzed with intracellular solution containing $100 \mu \mathrm{m}$ QX-314.D, Collected results (mean \pm SD) in nine cells with control solution, five cells dialyzed with $50 \mu \mathrm{m} Q \mathrm{QX}-314$, and three cells with $100 \mu \mathrm{m}$ QX-314.

no effect, and concluded that this occurs because the positively charged QX-314 enters the cells through the TRPV1 channel pore on its activation by capsaicin (Binshtok et al., 2007). To quantify the cytosolic levels of QX-314 that can be achieved by this mechanism, we now used quantitative mass spectrometry to measure intracellular QX-314 following TRPV1 activation with various concentrations of extracellular QX-314. After incubating rTRPV1-expressing CHO-cells with different concentrations of QX-314 and a fixed concentration of capsaicin ( $1 \mu \mathrm{M})$, we quantified intracellular QX-314 levels by LC-MS/MS. Over a broad extracellular concentration range (100 $\mu \mathrm{M}$ to $10 \mathrm{mM})$, we found that QX-314 accumulates in the presence of capsaicin in TRPV1expressing cells (Fig. $1 A$ ). In contrast, there was almost no QX314 entry in control cells (stable transfection with pcDNA3.1) up to concentrations of $5 \mathrm{~mm}$. At the highest concentration of extracellular QX-314 tested (10 mM), there was some accumulation of cellular QX-314 in the absence of TRPV1 but it was only 35\% of the cellular QX-314 achieved in the TRPV1-expressing cells at this concentration. Next, we measured relative concentrations of QX-314 in the membrane and cytosolic fractions of hTRPV1-expressing human embryonic kidney (HEK) cells by using ultracentrifugation to break up cells. Using $500 \mu \mathrm{M}$ extracellular QX-314, we found a 52-fold higher level of QX-314 in the cytosolic supernatant when TRPV1 was activated by cap- saicin than without capsaicin or when capsaicin and QX-314 were exposed to HEK cells not expressing TRPV1 (Fig. $1 B)$. There were also increased QX-314 concentrations in the membrane pellet after activation with capsaicin in transfected cells (Fig. 1C), but the amount was much lower than in the cytosolic fraction (Fig. $1 B)$, indicating that QX-314 accumulates primarily intracellularly.

To investigate how long QX-314 remains in HEK-293 cells after entering through TRPV1 channels, we quantified the QX-314 amount in cell lysates and in fresh culture media at different time points after incubation of hTRPV1expressing HEK-293 cells with QX-314 and capsaicin. QX-314 levels decreased over time in the cell lysates and increased commensurately in the culture medium (Fig. 1D). Importantly, we found that $50 \%$ of the cellular QX-314 still remained in cells after $\sim 72 \mathrm{~min}$. Measurement of capsaicin-induced QX-314 uptake in primary DRG revealed no significant increase (data not shown). Reasons for this may be the lower proportion of TRPV1expressing cells, fewer copy numbers of channels per cell, and higher basal QX314 concentrations resulting from nonspecific uptake in dead or dying cells.

\section{Kinetics of sodium channel block by TRPV1-mediated QX-314 uptake in DRG neurons}

To quantify the speed of entry of QX-314 through TRPV1 channels in DRG neurons, we examined the time course over which sodium channels are inhibited by QX-314 on entering through TRPV1 channels. QX-314 was coapplied with capsaicin to small DRG neurons expressing TRPV1 channels while evoking a voltage-dependent sodium current every second. Because the large nonvoltage-dependent TRPV1 current made it difficult to quantify the voltage-dependent sodium current while capsaicin is present, we used a protocol in which QX-314 and capsaicin were coapplied for $10 \mathrm{~s}$ followed by $40 \mathrm{~s}$ of washing with control solution, which reversed the TRPV1 activation and allowed accurate measurement of the voltagedependent sodium current. With this protocol, sodium current was substantially inhibited after a 10 s exposure to QX-314 and capsaicin. With repeated $10 \mathrm{~s}$ applications, there was further block (Fig. 2A). Exposure for $30 \mathrm{~s}$ resulted in block of sodium current to $24 \pm 8 \%(n=5)$ of control (Fig. $2 B)$. The block was dependent on the presence of both QX-314 and capsaicin, because when either agent was applied alone, there was only a small decrease in sodium current (Fig. $2 B$ ), which probably reflects slow rundown of the sodium current when it is stimulated steadily at $1 \mathrm{~Hz}$.

We estimated the concentration of intracellular QX-314 that accumulates in these experiments by using whole-cell recording dialysis of the intracellular solution to compare the sodium channel inhibition produced by direct application of QX-314 inside DRG neurons. Such whole-cell dialysis experiments showed that 

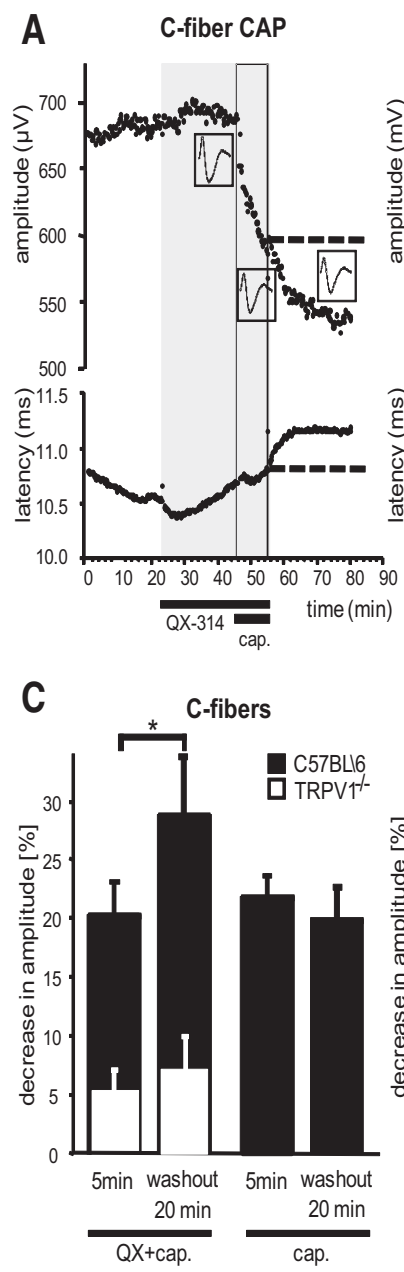

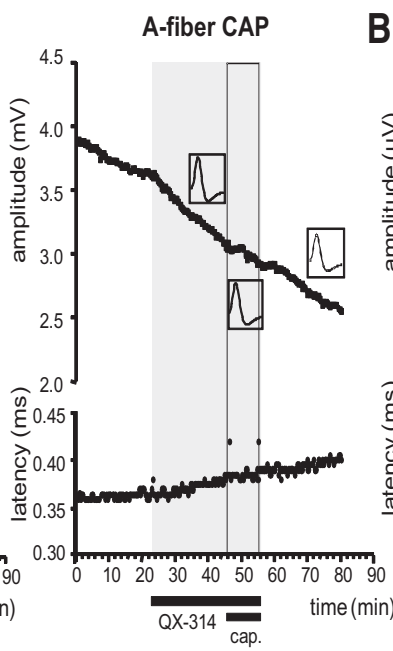

B

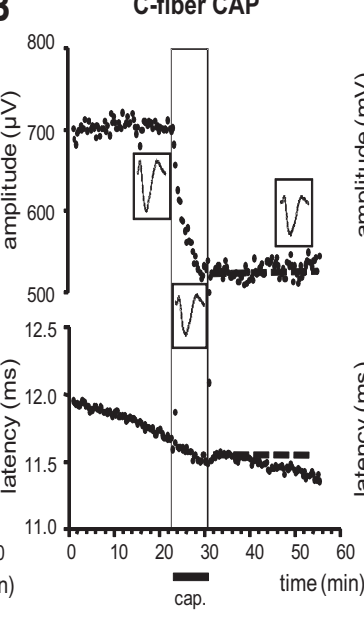

D

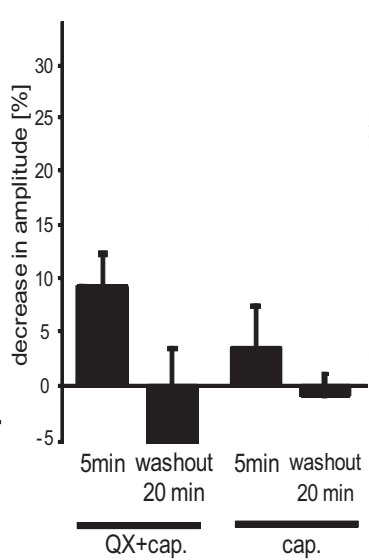

C-fibers

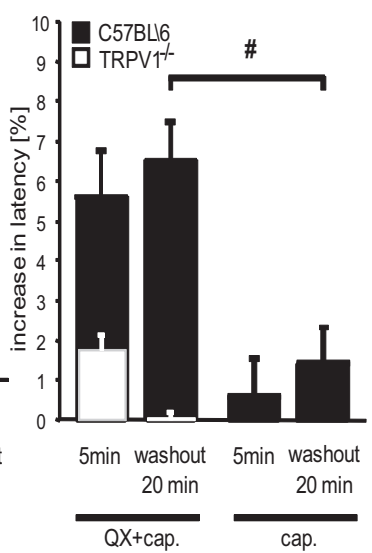

A-fiber CAP

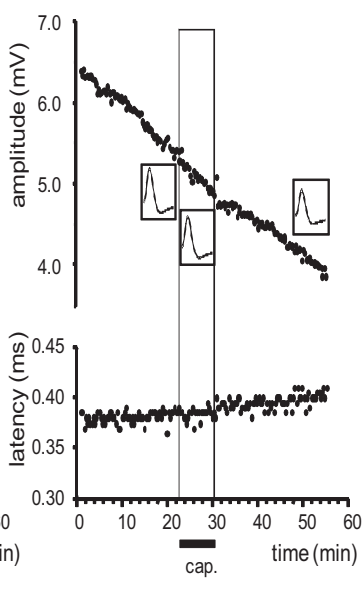

A-fibers

Figure 3. Effects of QX-314, its combination with capsaicin, and of capsaicin alone on amplitude and latency of the C-fiber and A-fiber Compound Action Potential (CAP) in C57BL 6 and TRPV1 ${ }^{-1-}$ mice. Isolated mouse sciatic nerves were superfused with QX-314 (300 $\left.\mu \mathrm{M}\right)$ and/or capsaicin (10 $\left.\mu \mathrm{M}\right)$ and CAPs recorded after electrical stimulation. $\boldsymbol{A}$, Representative trace of the amplitude (upper) and latency (lower) of the C-fiber and A-fiber CAP after superfusion with QX-314 followed by capsaicin. $B$, Same as in $\boldsymbol{A}$ but after superfusion with capsaicin only. C, Statistical analysis and comparison of CAP amplitudes from recordings after perfusion with QX-314 and capsaicin or capsaicin alone at the indicated time points from recordings as shown in $A$ and $B$ in $C 57 B L 16$ (black bars) and TRPV1 ${ }^{-1-}$ (white bar inserts) mice. $\boldsymbol{D}$, Statistical analysis and comparison of CAP latencies from recordings as shown in $A$ and $B$ in C57BL 6 (black bars) and TRPV1 ${ }^{-1-}$ (white bar inserts) mice. Data represent the means \pm SEM,$n=6-9$ C57BL $6 ; 3$ TRPV1 $^{-1-}$. Significance ${ }^{*} p<0.05$ calculated by Wilcoxon matched pairs testfor intraindividual; $\# p<0.01$ calculated by Mann-Whitney $U$ testfor group comparisons. cap., capsaicin.

$50 \mu \mathrm{M}$ internal QX-314 inhibited sodium current by more than half and $100 \mu \mathrm{M}$ internal QX-314 inhibited sodium current by $\sim 95 \%$ (Fig. 2C,D). Comparison of results in Figure 2A,B suggests that external QX-314 applied with capsaicin resulted in intracellular concentrations of $\sim 50 \mu \mathrm{M}$ or more.

Selective and prolonged conduction block of C-fiber axons by QX-314 and capsaicin

To investigate the effects of TRPV1-mediated QX-314 uptake on nerve conduction, electrically evoked CAPs from isolated mouse sciatic nerves were recorded. Superfusion with $300 \mu \mathrm{M}$ QX-314 induced no changes in amplitude or latency of C-fiber and A-fiber CAPs (Fig. 3A). However, QX-314 in combination with $10 \mu \mathrm{M}$ capsaicin produced a selective and substantial reduction in the amplitude of the C-fiber CAP, which began immediately with the application and progressively declined further over the 10 min of superfusion. In addition, the C-fiber CAP showed a progressive increase in latency, which may reflect typical local anesthetic changes produced by QX-314 entry reducing sodium currents and by that means, conduction velocity (Kistner et al.,
2010; Leffler et al., 2011). Over a subsequent $20 \mathrm{~min}$ washout period, the decrease in the amplitude as well as the increase in the latency of the C-fiber CAP progressed further and did not recover, in keeping with accumulation of intra-axonal QX-314, which does not reverse quickly. In contrast, the CAP responses of the myelinated A-fibers of the same nerve were not affected by application of QX-314 combined with capsaicin. There was a time-dependent rundown in the A-fiber CAP, but it occurred with a rate unaffected by the application of capsaicin or QX-314 either separately or together.

To evaluate the amount of a combinatorial effect with QX314 , we next tested capsaicin alone. Capsaicin produced a progressive depression in the amplitude of the C-fiber CAP (Fig. 3B). However, this effect, unlike the capsaicin-QX-314 combination, was short-lasting and partially reversible during the $20 \mathrm{~min}$ washout phase. In addition, the C-fiber CAP latency was affected to a much lesser extent by capsaicin alone than by capsaicin and QX-314. The reduction of CAP by capsaicin alone may reflect depolarization of TRPV1-expressing C-fibers and subsequent depolarization block by sodium channel inactivation (Petsche et al., 
1983). As expected, capsaicin did not affect the amplitude and the latency of the A-fiber CAP response. Quantitative analysis revealed an initial reduction of the C-fiber CAP amplitude to approximately the same extent by capsaicin alone compared with its combination with QX-314 at 5 min (capsaicin, $21.7 \pm 2.0 \%$; capsaicin and QX-314, $20.1 \pm 3.0 \%$ ) (Fig. 3C). However, after 20 min washout the decrease in $\mathrm{C}$-fiber amplitude induced by capsaicin alone showed partial recovery while that induced by the combination with QX-314 remained significantly lower (capsaicin, $19.8 \pm 2.9 \%$; capsaicin and QX-314, $28.8 \pm 5.0 \% ; n=9$, $\left.{ }^{*} p<0.05\right)$. Interestingly, a significant increase in the latency of the C-fiber CAP was not observed after capsaicin alone application (capsaicin, $0.6 \pm 1.0 \%$; capsaicin and QX-314, $5.6 \pm 1.2 \%$, $n=6$, $\# p<0.01$ ) but only in combination with QX-314 (Fig. $3 D$ ). Because not all C-fibers express TRPV1, these results underestimate the changes in these particular fibers.

To confirm the essential role of TRPV1 in generating the blocking effects of QX-314 in combination with capsaicin on C-fibers, TRPV1 ${ }^{-/-}$mice were examined (Fig. $3 C, D$, white bars). As expected, QX-314 together with capsaicin showed negligible effects in these mice both on the amplitude and the latency of the $\mathrm{C}$-fiber CAP at $5 \mathrm{~min}$ after application and after a $20 \mathrm{~min}$ washout (amplitude, $5.2 \pm 1.5 \mathrm{mV}$; latency, $1.7 \pm 0.3 \mathrm{~ms} ; n=3$ ).

\section{Effects of axonal silencing of TRPV1-expressing sensory neurons on acute nociceptive responses elicited by intraplantar injection of capsaicin}

To investigate whether the activity of TRPV1-expressing neurons can be blocked by a perisciatic QX314 and capsaicin combination in vivo, we quantified changes in acute pain-like responses evoked by an injection of capsaicin intradermally into the lateral plantar surface of the left hindpaw (in the sciatic nerve terminal field). Following intraplantar capsaicin injection $1 \mathrm{~h}$ after perisciatic application of vehicle, rats showed brisk leg-lift responses (10.5 \pm $2.3)$ and bouts of licking $(20.8 \pm 6.8 \mathrm{~s})$ over a 15 min observation period (Fig. $4 A, B$ ). In contrast, $1 \mathrm{~h}$ after perisciatic application of QX-314 and capsaicin, these responses to peripheral capsaicin were strongly reduced for both the lifts $(2.5 \pm 0.67)$ and paw licking $(1.3 \pm 1.2 \mathrm{~s})$. We conclude that the axonal silencing strategy blocks nerve conduction in TRPV1-expressing nociceptors in an efficient manner in vivo.

\section{Sensory and motor changes after silencing TRPV1-expressing sensory neurons}

We next studied the effect on sensory function of temporarily "silencing" the axons of TRPV1-expressing neurons in the rat sciatic nerve in vivo by perisciatic injection of the combination of QX-314 and capsaicin. Behavioral testing was focused only on the lateral side of the hindpaw, which is completely innervated by the sciatic nerve. Perisciatic injection of QX-314 followed by vehicle did not significantly alter the responsiveness of the rats to any mechanical (pinch, pinprick, light touch) or thermal (radiant heat) stimuli used. Similarly, injection of saline followed by capsaicin did not have any significant effect on these outcome measures. Injection of QX-314 followed by capsaicin, however, induced a profound hypoalgesia to radiant heat, with the response latency approaching (and in some animals reaching) the cutoff. This lasted for a minimum of $7 \mathrm{~h}$, with full recovery at $24 \mathrm{~h}$ (Fig. 5A). An equally pronounced hypoalgesia with similar duration was also found to pinch stimuli, with the threshold more than doubling (Fig. 5B). Interestingly, in contrast to a pinch, the nociceptive response to pinprick stimulation was completely unaffected by the QX-314-capsaicin combination (Fig. 5C). As ex-
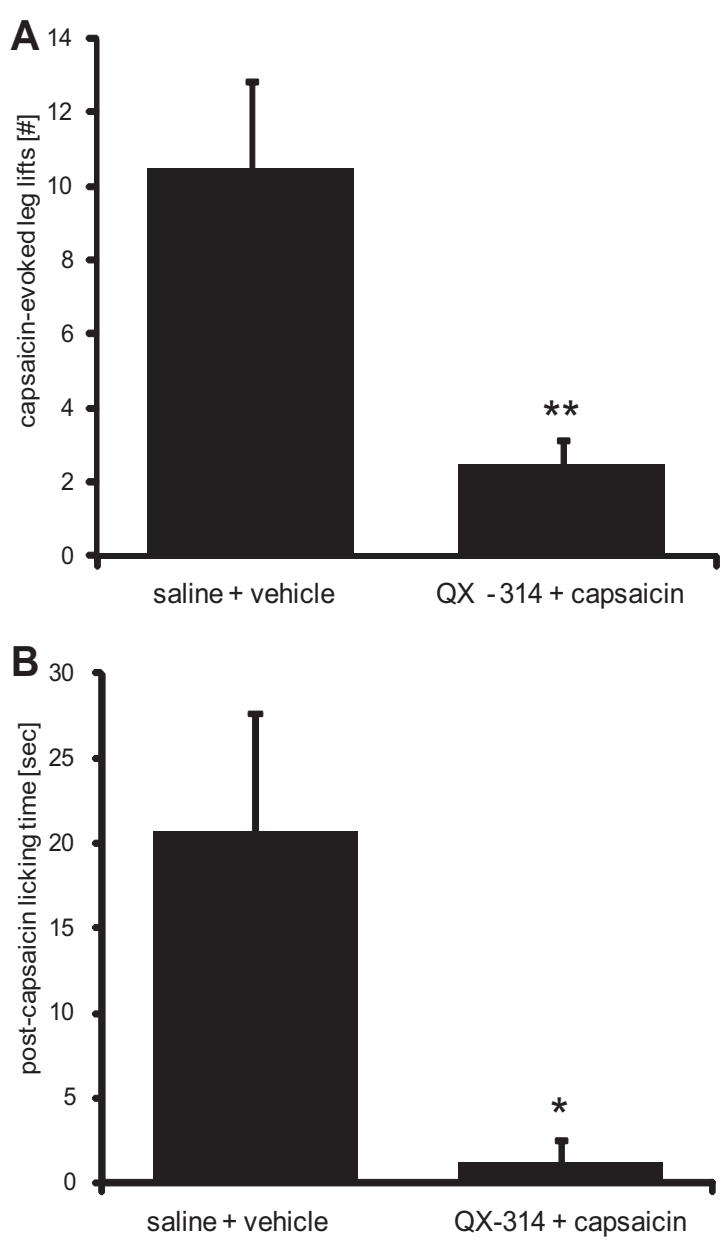

Figure 4. Effects of axonal silencing of TRPV1-expressing sensory neurons on acute nociceptive responses elicited by intraplantar injection of capsaicin. $\boldsymbol{A}, \boldsymbol{B}$, One hour after silencing TRPV1-expressing neurons by injection of $200 \mu \mathrm{l}$ of $0.5 \%$ QX-314 followed by $200 \mu \mathrm{l}$ of $0.05 \%$ capsaicin (controls received saline followed by vehicle) into the sciatic notch intraplantar capsaicin $(0.005 \%, 20 \mu l)$ was injected into the hindpaw and over a 15 min observation period, the number of paw lifts $(\boldsymbol{A})$ or the total duration of licking bouts $(\boldsymbol{B})$ was analyzed. Data represent the average \pm SEM from six animals per group. Significance was calculated by two-tailed Student's $t$ test. ${ }^{*} p<0.05$ and ${ }^{* *} p<0.01$ compared with saline and vehicle injection.

pected, behavioral responses to light touch, which is mainly mediated by $\mathrm{A} \beta$-fibers (Schmelz, 2011), were not altered by the QX-314-capsaicin combination (Fig. 5D) nor were there any changes in motor function (Fig. $5 E$ ). In contrast, perisciatic injection of $2 \%$ lidocaine produced a complete, short-lasting nonselective block of all motor (Fig. 5E) and sensory functions (data not shown). To confirm that the radiant heat and pinch analgesia induced by the combination of QX-314 and capsaicin was mediated by an open TRP-channel pore, we coinjected the two with ruthenium red (RR), a TRP-channel pore blocker. One millimole RR prevented the effect of the combination, with no effect on its own (Fig. $5 F, G$ ). Collectively these data indicate that sensory responses evoked by pinch or noxious heat stimuli are mediated by TRPV1-expressing axons while those by pinprick or light touch are carried by non TRPV1-expressing afferent fibers.

TRPV1-expressing neurons contribute to mechanical and thermal inflammatory pain hypersensitivity

Two days after the induction of peripheral inflammation by intraplantar CFA administration, animals showed reduced radiant heat and mechanical (pinch, von Frey) pain thresholds (Fig. 6A- 
C). Silencing TRPV1-expressing axons by perisciatic QX-314-capsaicin injections resulted in a complete and long-lasting $(\geq 5 \mathrm{~h}$ ) analgesia to radiant heat, pinch, and tactile (von Frey) stimulations, not only reversing the inflammatory hypersensitivity, but producing a complete block in sensitivity to these stimuli, exactly as in naive animals. Next, we investigated the effect of the combination of these drugs on cold pain hypersensitivity. Naive rats did not show any flinch responses when placed on a cold plate with a surface temperature of $5^{\circ} \mathrm{C}$ for $5 \mathrm{~min}$ (Fig. $6 D)$. However, $2 \mathrm{~d}$ after CFA injection, nociceptive responses were elicited, and these were significantly reduced by the QX-314-capsaicin combination.

QX-314 alone produced no significant effect in the Hargreaves (Fig. 6A), pinch (Fig. 6B), von Frey (Fig. 6C), or cold plate (Fig. 6D) tests, but capsaicin injection alone resulted in a small effect on thermal (heat and cold) responsiveness (Fig. $6 A, D)$, but not to mechanical stimulation (Fig. 6B,C). We conclude that TRPV1expressing axons transfer all the hot, cold, and mechanical evoked signals during inflammation that contribute to the inflammatory pain hypersensitivity phenotype.

\section{The effect of silencing TRPV1- expressing neurons on neuropathic pain}

In rodent models of peripheral neuropathic pain, as in human patients, tactile and cold allodynia are prominent features (Matsumoto et al., 2008). To determine whether TRPV1-expressing neurons contribute to this pain hypersensitivity phenotype, we injected the perisciatic QX-314-capsaicin combination in rats with the SNI model of neuropathic pain $8 \mathrm{~d}$ after surgery. Before the perisciatic injection, the rats exhibited reduced thresholds to a pinch stimulus and tactile (reduced von Frey threshold) and cold allodynia (enhanced response to acetone) (Fig. $7 A-C$ ) but no reduced heat threshold (data not shown), as expected (Decosterd and Woolf, 2000). The QX-

314-capsaicin combination produced a complete and long-lasting block of responsiveness to pinch (Fig. 7A) and to radiant heat stimulation (data not shown), exactly as in naive animals. In contrast, the reduced von Frey thresholds (a measure of static punctate mechanical allodynia) after SNI, although significantly reduced after perineural capsaicin-QX-314 coadministration, did not reach values higher than those obtained before the nerve injury (i.e., no analgesia, rather a return to baseline). This result differed from that in naive animals where capsaicin-QX-314 coadministration causes von Frey thresholds to increase very substantially above baseline (i.e., produces analgesia) (Binshtok et al., 2007), as we also found during inflammation, with a $>6$-fold increase in threshold above baseline (Fig. 6C). These findings imply a substantial contribution ofTRPV1-
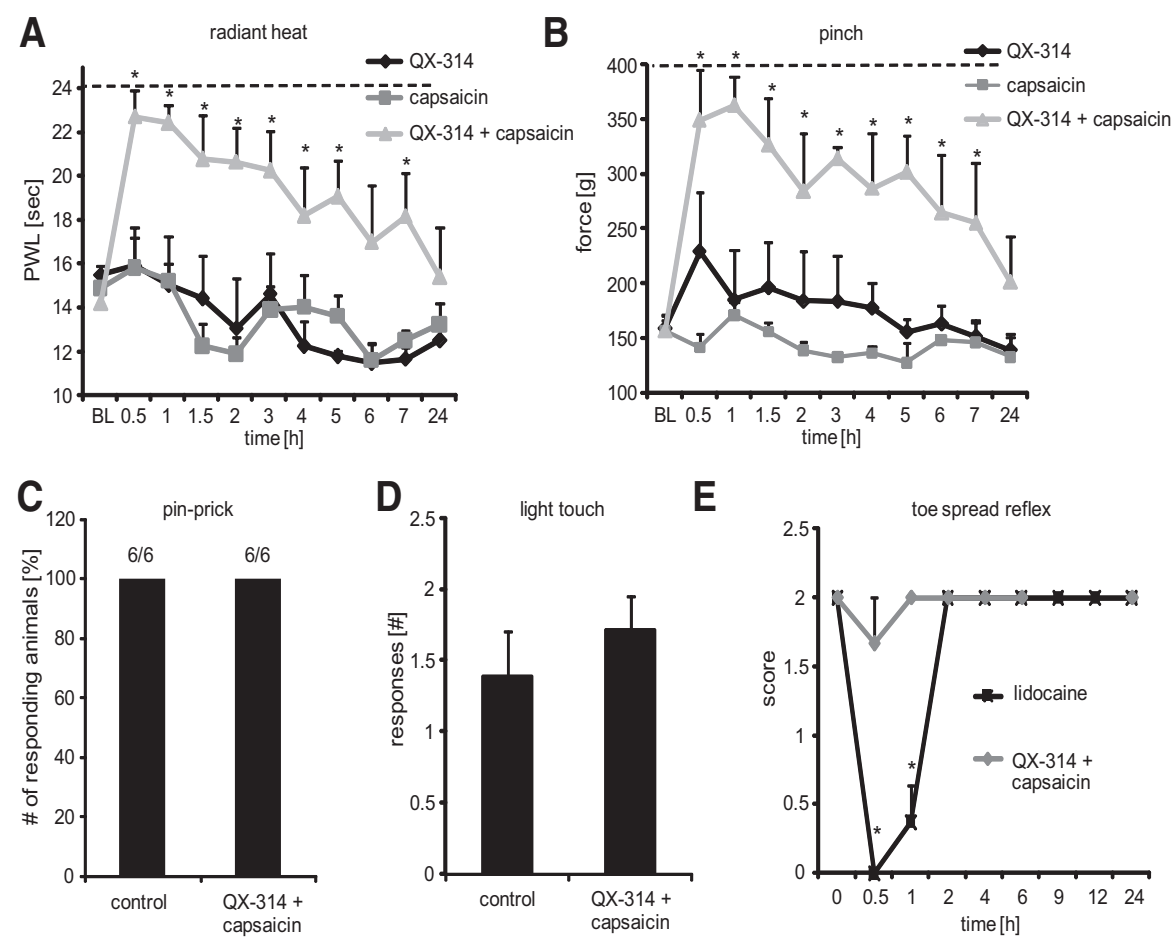

E
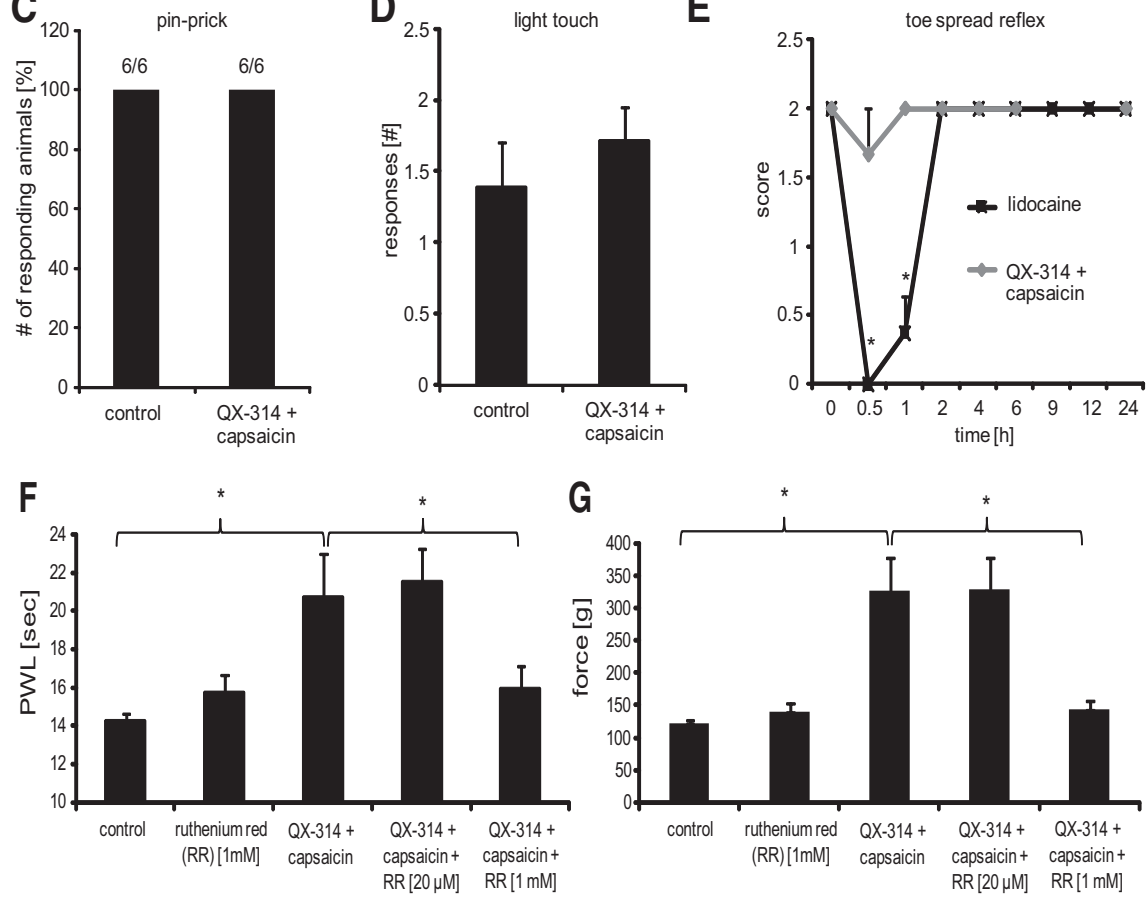

Figure 5. Sensory processing of TRPV1-expressing neurons in naive rats. Behavioral responses were determined after silencing TRPV1expressing neurons by injection of $200 \mu \mathrm{l}$ of $0.5 \%$ QX-314 followed by $200 \mu \mathrm{l}$ of $0.05 \%$ capsaicin into the sciatic notch. Different sensory ns were applied to the lateral paw. $A$, Thermal thresholds after radiant heat stimuli. At the indicated time points, paw withdrawa latencies were determined using the Hargreaves test. $\boldsymbol{B}$, Mechanical threshold after nociceptive stimulation with an increasing force using a pincher.C, Nociceptive responses after mechanical stimuli induced by a pinprick at $1 \mathrm{~h}$ after perineural injections. 6/6, Six rats of six showed hawal response. $\boldsymbol{D}$, Paw withdrawal responses to light touch stimulations with a brush. Average number of responses to five 列 政 $\boldsymbol{G}$, pinch test as in $\boldsymbol{B}$ ) were determined. In all experiments, data represent the average \pm SEM from six animals per group. significance was calculated by the two-way repeated-measures ANOVA and Bonferroni correction. ${ }^{*} p<0.05$ compared with saline and vehicle injection. The dashed line indicates the cutoff. PWL, Paw Withdrawal Latency.

expressing axons in mediating mechanical sensitivity in naive and inflamed animals and less so after nerve injury. Cold allodynia, indicated by strong flinching and paw-licking after applying a drop of acetone to the lateral paw, was completely unaffected by the silencing of TRPV1-expressing neurons in the SNI animals, indicating that this component of stimulus-evoked neuropathic pain is not processed by TRPV1-expressing sensory neurons, even though cold hypersensitivity was completely blocked after inflammation (Fig. 6D).

\section{Discussion}

We have investigated the sensory functions mediated by TRPV1expressing primary afferent neurons in response to noxious stimuli, and also in generating inflammatory and neuropathic pain 

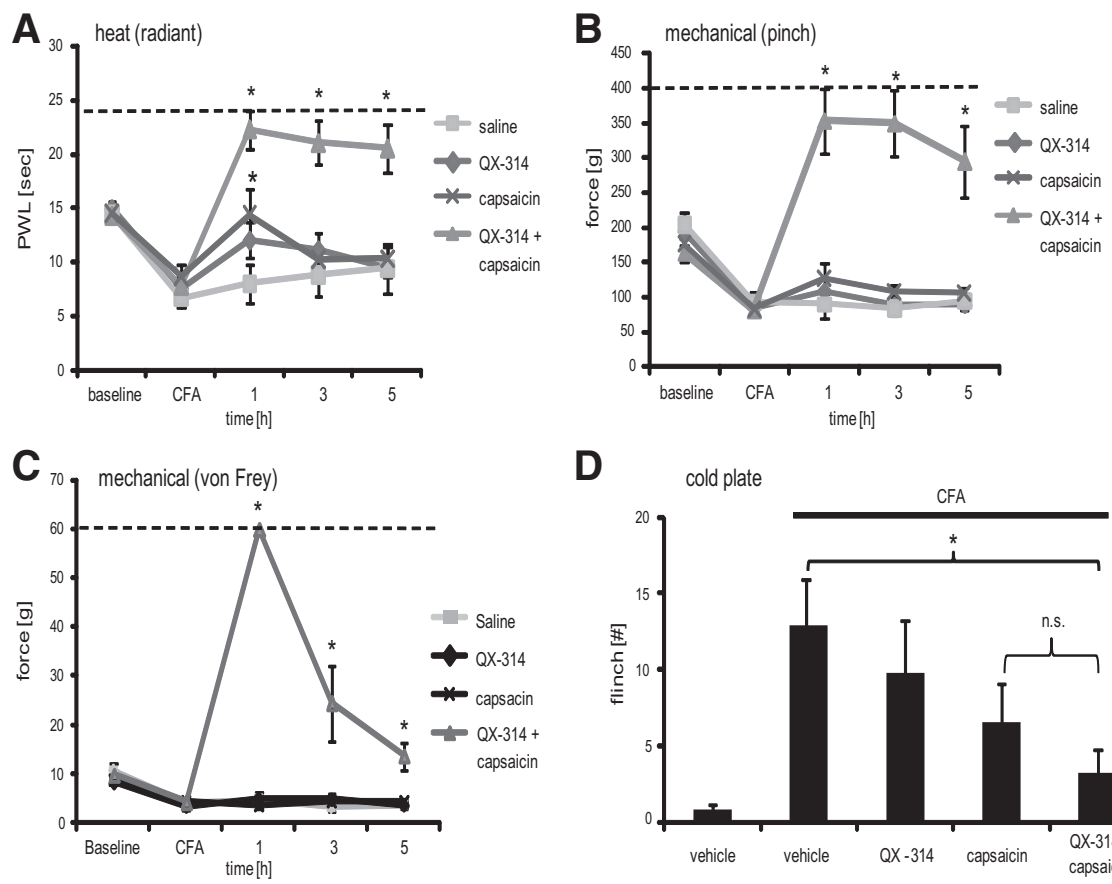

D

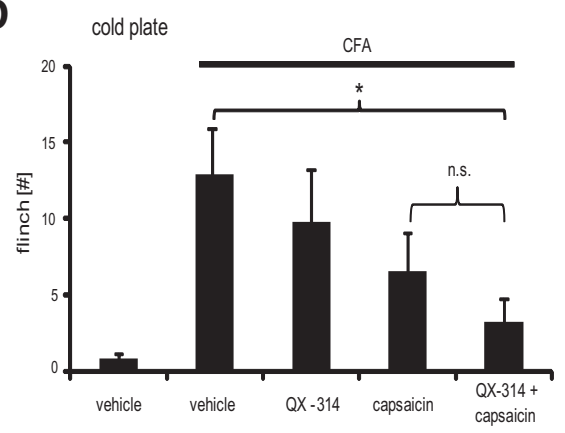

Figure 6. TRPV1-expressing neurons process heat, mechanical, and cold hyperalgesia during inflammation. At $48 \mathrm{~h}$ after intraplantar injection of $100 \mu \mathrm{l}$ of CFA, TRPV1-expressing neurons were silenced by injection of $200 \mu \mathrm{l}$ of $0.5 \%$ QX-314 followed by $200 \mu \mathrm{l}$ of $0.05 \%$ capsaicin into the sciatic notch and then behavioral responses determined. $\boldsymbol{A}$, Heat hyperalgesia. Thermal thresholds were determined after radiant heat stimulation to the lateral paw in the Hargreaves test. $\boldsymbol{B}$, Mechanical hyperalgesia. Mechanical thresholds were determined after stimulation of the lateral paw with an increasing force by a pincher. $\boldsymbol{C}$, Tactile allodynia. Mechanical thresholds were determined after stimulating the lateral paw with von Frey filaments. D, Cold hyperalgesia. The number of flinches observed during $5 \mathrm{~min}$ on $5^{\circ} \mathrm{C}$ cold plate was counted at $1 \mathrm{~h}$ after silencing. Data represent the average \pm SEM from 6 to 12 rats per group. In all temporal courses, significance was calculated by the two-way repeated-measures ANOVA and Bonferroni correction. ${ }^{*} p<0.05$ compared with CFA without perineural injections. The dashed line indicates the cutoff. Cold plate experiments were analyzed using a one-way ANOVA followed by Bonferroni post hoc test.

hypersensitivity. Instead of a complete irreversible ablation of these neurons, we selectively silenced action potential conduction in the investigated cell population pharmacologically. This provides a more rapid test of the functional sensory role of specific fibers, which reduces the possibility of adaptive changes that might occur with complete ablation over days.

We previously reported that QX-314 selectively blocks sodium currents in small DRG neurons only when applied together with the selective TRPV1 agonist capsaicin. The simplest explanation was that QX-314 enters into TRPV1-expressing nociceptors via the TRPV1 channel pore to block voltagegated sodium channels from the internal surface (Binshtok et al., 2007). Using mass spectroscopy analytics, we now show directly that QX-314 accumulates inside cells in a manner depending on TRPV1 expression and its activation by capsaicin. In TRPV1-expressing HEK cells, highly selective increases of intracellular QX314 concentrations were achieved from $10 \mathrm{~min}$ of exposure to external QX-314 at 0.1-5 mM. Experiments in DRG neurons using block of sodium current as an assay allowed faster resolution and showed that intracellular QX-314 concentrations of $\sim 50 \mu \mathrm{M}$ are achieved within $30 \mathrm{~s}$ of exposure to QX-314-capsaicin. It should be noted that the spherical DRG cell bodies have a far smaller surface-to-volume ratio than axons, so equivalent entry through axonal membrane would be expected to result in a much more rapid increase in internal QX-314 concentration in vivo. Once loaded, the effect of intracellular QX-314 is expected to be long-lasting. After loading HEK-293 cells with QX-314 upon TRPV1 activation, the half-life of the release of QX-314 was much longer (72 $\mathrm{min})$ than the uptake period (10 min), suggesting that QX-314 is trapped intracellularly due to slow efflux pathways.

Our studies on propagated action potentials in isolated sciatic nerves showed that the combination of QX-314 and capsaicin slows CAP propagation and decreases CAP amplitude. Not all C-fibers are TRPV $1^{+}$, so the effect detected in the compound action potential recordings reflects changes in TRPV ${ }^{+}$and no effect in TRPV1 ${ }^{-}$axons, hence the lack of complete block of the CAP. Capsaicin alone also decreased CAP amplitude, presumably by depolarizing TRPV1-containing C-fibers and inactivating sodium channels. However, QX-314 coapplied with capsaicin gave an effect that persisted much longer than that of capsaicin alone, consistent with trapping of QX-314 inside $\mathrm{C}$-fiber axons. Sodium channel block by QX-314 is strongly use-dependent (Ragsdale et al., 1994) and consequently depolarization and spiking resulting from TRPV1 activation by capsaicin will enhance blocking by intracellular QX-314. Recovery from use-dependent enhancement of QX-314 block is very slow (many minutes) (Ragsdale et al., 1994), reflecting trapping of QX-314 molecules in closed sodium channels (Hille, 1977), helping maintain nerve block once it is achieved.

We therefore used this technique to phenotype the sensory function of TRPV1-expressing nociceptors, in the context of their contribution to the coding of specific nociceptive, inflammatory, and neuropathic pain qualities. Perineural injection of QX-314 and capsaicin almost completely eliminated the acute pain-related behavior evoked by peripheral intraplantar capsaicin injection, which demonstrates the efficiency of the strategy for silencing TRPV1-expressing neurons in vivo.

Neurons that express defined sensory transducer channels will likely be activated by specific stimuli at the particular intensities that the transducer is adapted to respond to. In the case of TRPV1, this would be noxious heat $>42^{\circ} \mathrm{C}$, and this activation may result in an awareness of heat pain (Caterina et al., 2000). Does this mean that TRPV1 is the heat-pain sensor and conversely that only heat pain is encoded by TRPV1-expressing sensory neurons? A large proportion of capsaicin-responsive C-fiber neurons are polymodal and can be activated by hot and cold temperatures as well as by mechanical stimuli (Szolcsanyi et al., 1988; Perl, 1996; Handwerker, 2008). However, more recent studies have found TRPV1-expressing afferents to be heat responsive and mechanically insensitive (Lawson et al., 2008). Yet another study found rather surprisingly that TRP channel block with RR did not reduce heat-induced firing of isolated sensory fibers (St Pierre et al., 2009) while two other studies established that C-polymodal fibers provide identical noxious heat responses in TRPV1 knock-out and wild-type mice, but that only wild-type fibers became sensitized to heat by a TRPV1 agonist (Woodbury et al., 2004; Zimmermann et al., 2005). Inflammation induced by complete Freund's adjuvant was found in one study to sensitize 

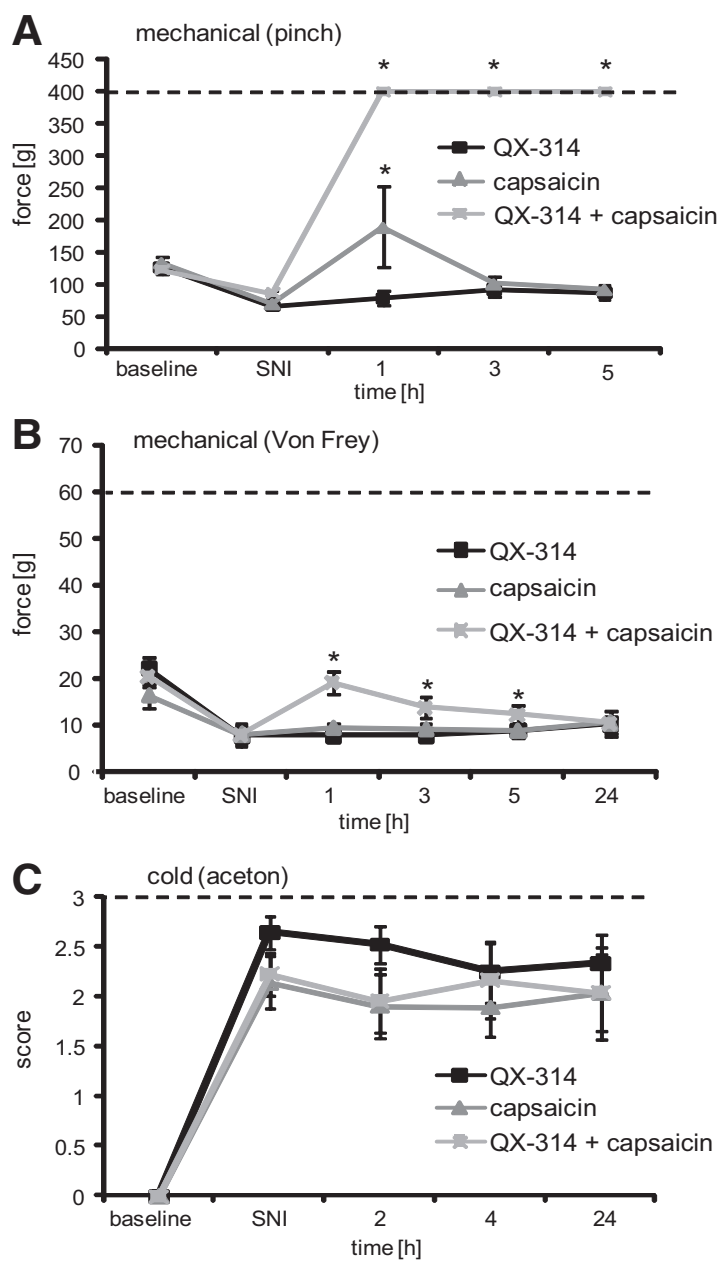

Figure 7. TRPV1-expressing neurons do not mediate cold allodynia in the SNI model. At day 8 after SNI surgery, TRPV1-expressing neurons were silenced by injection of $200 \mu \mathrm{l}$ of $0.5 \%$ QX-314 followed by $200 \mu \mathrm{l}$ of $0.05 \%$ capsaicin into the sciatic notch and behavioral responses determined after sensory stimulation to the lateral paw. $\boldsymbol{A}$, Mechanical hyperalgesia. Mechanical thresholds were determined after stimulation with an increasing force by a pincher. $\boldsymbol{B}$, Tactile allodynia. Mechanical thresholds were determined by the von Frey test. C, Cold allodynia. Nociceptive responses induced by a drop of acetone were determined. Data represent the average \pm SEM from 6 to 10 rats per group. Significance was calculated by the two-way repeated-measures ANOVA and Bonferroni correction. ${ }^{*} p<0.05$ compared with SNI without perineural injections. The dashed line indicates the cutoff.

only TRPV1 ${ }^{-}$polymodal C-fibers (Koerber et al., 2010). All these reports, together with the lack of a complete loss of heat pain in TRPV1 knock-out mice but a loss of heat hyperalgesia in inflamed TRPV ${ }^{-1-}$ animals (Caterina et al., 2000), make the role of TRPV 1 as the primary nociceptive heat-pain transducer somewhat controversial. Because TRPV1-mediated axonal silencing resulted in a complete loss of noxious heat sensitivity, we conclude however, that neurons expressing TRPV1 do process intense heat stimuli, although whether this is through TRPV1 or not is not addressed by this approach.

Silencing TRPV1-expressing axons also abolished the response to mechanical pressure with a pinch forceps, but the response to brush or pinprick remained intact. These results suggest that only pain induced by firm mechanical pressure is processed by TRPV1-expressing C-fiber neurons, at least in rats. These results differ from those found with ablation of TRPV1expressing neurons in mice, which failed to find any mechanical deficit (Mishra and Hoon, 2010; Mishra et al., 2011), possibly a reflection of the mechanical test used (more like pinprick than pressure). A confounding element in studies looking at the functional coding of different sensory neurons is species differences. Rats exhibit a higher number of TRPV1-expressing neurons than mice and TRPV1 is expressed in some nonpeptidergic isolectin B4-positive rat neurons, known to process mechanical pain perception (Price and Flores, 2007).

TRPV1 expression in many nociceptors is transient in the embryo (such as in TRPM8-expressing and Mrg-expressing afferents) and ablation during early development will eliminate not only fibers that continue to be TRPV1-expressing fibers in the adult but also all neurons that have some TRPV1 expression at any point in their differentiation lineage (Mishra et al., 2011). Researchers have ablated TRPV1 afferents in adult mice using the neurotoxic effects of a high dose of capsaicin or resiniferatoxin. These experiments have revealed a selective role for these afferents in thermal but not mechanical pain sensitivity (Scherrer et al., 2009; Mishra and Hoon, 2010), although the extent of the damage is not clear, nor are its secondary effects, including possible immune cell activation. Deletion of $\mathrm{Na}_{(\mathrm{v})} 1.8$-expressing primary sensory cells, which includes many TRPV1-expressing neurons (Agarwal et al., 2007), abolished the response to noxious mechanical pressure and cold pain (Abrahamsen et al., 2008). Unexpectedly, in this study, acute heat responses remained intact while heat hyperalgesia was blocked.

During inflammation, the combination of QX-314 and capsaicin completely blocked responses to heat and cold hyperalgesia, as previously reported after ablation (Mishra and Hoon, 2010; Mishra et al., 2011). This implies that the TRPV1expressing cell population mediates thermal (heat and cold) hyperalgesia. Supporting this, $\mathrm{TRPM}^{+}$and $\mathrm{TRPAl}^{+}$neurons, which may mediate cold pain (Kwan et al., 2006; Bautista et al., 2007; del Camino et al., 2010), do appear to largely coexpress TRPV1. After CFA injection, mechanical pain responses to stimulation with von Frey filaments or a pinch forceps were markedly sensitized and these were completely blocked by QX-314 and capsaicin. The CFA experiments indicate that, during inflammation, TRPV1 ${ }^{+}$nociceptors still contribute to the same heat and mechanical modalities seen in naive rats and the sensitized state does not reflect recruitment of non-TRPV ${ }^{+}$fibers.

In the SNI model of peripheral neuropathic pain, light touch or cool stimulation induce nociceptive-like responses (Decosterd and Woolf, 2000). Silencing TRPV1 axons had no effect on cold allodynia during neuropathy, quite unlike the inflammatory state, indicating that sensory neurons other than TRPV1 axons contribute to this phenotype. We also found that selective silencing of sciatic TRPV1 axons had complex effects on mechanical sensitivity: it induced an absolute blockade of the responses to pinch as in naive animals, but had only a relatively small effect on the response to a punctate static mechanical (von Frey) stimulus. The silencing of TRPV1 axons reduced the heightened sensitivity to such stimuli (reversing the mechanical allodynia) but did not abolish this form of mechanical sensitivity, as found in naive or inflamed animals. One possibility is that after nerve injury, static mechanical pain hypersensitivity involves TRPV ${ }^{-}$fibers, either low-threshold $\mathrm{A} \beta$ or $\mathrm{C}$ mechanoreceptors (Matsumoto et al., 2008; Xie et al., 2008; Seal et al., 2009). Whether TRPV1 is upregulated in neuropathic A-fibers is a matter of ongoing study, but upregulation in C-fibers innervating chronically inflamed tissues has been reported (Ji et al., 2002). This may cause an increase in the efficacy of the QX-314-capsaicin combination during inflammatory conditions. If A-fibers began to express TRPV1 after nerve injury, the expectation would be that tactile 
responsiveness would be effectively blocked, which is something we did not observe.

In conclusion, using tandem mass spectrometry and electrophysiology we have demonstrated the selectivity and potency of cationic drugs introduced into defined neurons via TRPV1. Furthermore, we have used this technique to acutely silence TRPV1expressing axons in vivo. The sensory deficits that result suggest that TRPV1-expressing afferents in the rat are necessary for noxious heat and mechanical nociceptive sensations in naive animals, and heat, cold, and mechanical hypersensitivity in inflamed rats. In contrast, in a model of peripheral neuropathic pain, sensitivity to static punctate mechanical stimuli and cold allodynia must be processed by TRPV1 ${ }^{-}$fibers, indicating a dynamic alteration in sensory channels after nerve injury and suggesting that cold and tactile allodynia are state-dependent. For a more complete phenotyping of the somatosensory system, the extension of the silencing technique to other sensory fibers, such as those expressing TRPM8 or TRPA1, would be ideal. However, the pores of TRPM8 or TRPA1 may have different permeability properties than TRPV1 (Chen et al., 2009; Banke et al., 2010) and it remains to be seen whether they are sufficiently permeable to QX-314 to permit the same approach.

\section{References}

Abrahamsen B, Zhao J, Asante CO, Cendan CM, Marsh S, Martinez-Barbera JP, Nassar MA, Dickenson AH, Wood JN (2008) The cell and molecular basis of mechanical, cold, and inflammatory pain. Science 321:702-705. CrossRef Medline

Agarwal N, Pacher P, Tegeder I, Amaya F, Constantin CE, Brenner GJ, Rubino T, Michalski CW, Marsicano G, Monory K, Mackie K, Marian C, Batkai S, Parolaro D, Fischer MJ, Reeh P, Kunos G, Kress M, Lutz B, Woolf CJ, et al. (2007) Cannabinoids mediate analgesia largely via peripheral type 1 cannabinoid receptors in nociceptors. Nat Neurosci 10: 870-879. CrossRef Medline

Allchorne AJ, Broom DC, Woolf CJ (2005) Detection of cold pain, cold allodynia and cold hyperalgesia in freely behaving rats. Mol Pain 1:36. CrossRef Medline

Banke TG, Chaplan SR, Wickenden AD (2010) Dynamic changes in the TRPA1 selectivity filter lead to progressive but reversible pore dilation. Am J Physiol Cell Physiol 298:C1457-C1468. Medline

Bautista DM, Siemens J, Glazer JM, Tsuruda PR, Basbaum AI, Stucky CL, Jordt SE, Julius D (2007) The menthol receptor TRPM8 is the principal detector of environmental cold. Nature 448:204-208. CrossRef Medline

Binshtok AM, Bean BP, Woolf CJ (2007) Inhibition of nociceptors by TRPV1-mediated entry of impermeant sodium channel blockers. Nature 449:607-610. CrossRef Medline

Binshtok AM, Gerner P, Oh SB, Puopolo M, Suzuki S, Roberson DP, Herbert T, Wang CF, Kim D, Chung G, Mitani AA, Wang GK, Bean BP, Woolf CJ (2009) Coapplication of lidocaine and the permanently charged sodium channel blocker QX-314 produces a long-lasting nociceptive blockade in rodents. Anesthesiology 111:127-137. CrossRef Medline

Bráz JM, Basbaum AI (2009) Triggering genetically-expressed transneuronal tracers by peripheral axotomy reveals convergent and segregated sensory neuron-spinal cord connectivity. Neuroscience 163:1220-1232. CrossRef Medline

Bremer M, Fröb F, Kichko T, Reeh P, Tamm ER, Suter U, Wegner M (2011) Sox10 is required for Schwann-cell homeostasis and myelin maintenance in the adult peripheral nerve. Glia 59:1022-1032. CrossRef Medline

Bretag AH (1969) Synthetic interstitial fluid for isolated mammalian tissue. Life Sci 8:319-329. CrossRef Medline

Caterina MJ, Leffler A, Malmberg AB, Martin WJ, Trafton J, Petersen-Zeitz KR, Koltzenburg M, Basbaum AI, Julius D (2000) Impaired nociception and pain sensation in mice lacking the capsaicin receptor. Science 288: 306-313. CrossRef Medline

Cavanaugh DJ, Lee H, Lo L, Shields SD, Zylka MJ, Basbaum AI, Anderson DJ (2009) Distinct subsets of unmyelinated primary sensory fibers mediate behavioral responses to noxious thermal and mechanical stimuli. Proc Natl Acad Sci U S A 106:9075-9080. CrossRef Medline

Chen J, Kim D, Bianchi BR, Cavanaugh EJ, Faltynek CR, Kym PR, Reilly RM
(2009) Pore dilation occurs in TRPA1 but not in TRPM8 channels. Mol Pain 5:3. CrossRef Medline

Clapham DE (2007) SnapShot: mammalian TRP channels. Cell 129:220. Medline

Davis JB, Gray J, Gunthorpe MJ, Hatcher JP, Davey PT, Overend P, Harries MH, Latcham J, Clapham C, Atkinson K, Hughes SA, Rance K, Grau E, Harper AJ, Pugh PL, Rogers DC, Bingham S, Randall A, Sheardown SA (2000) Vanilloid receptor-1 is essential for inflammatory thermal hyperalgesia. Nature 405:183-187. CrossRef Medline

Decosterd I, Woolf CJ (2000) Spared nerve injury: an animal model of persistent peripheral neuropathic pain. Pain 87:149-158. CrossRef Medline

del Camino D, Murphy S, Heiry M, Barrett LB, Earley TJ, Cook CA, Petrus MJ, Zhao M, D’Amours M, Deering N, Brenner GJ, Costigan M, Hayward NJ, Chong JA, Fanger CM, Woolf CJ, Patapoutian A, Moran MM (2010) TRPA1 contributes to cold hypersensitivity. J Neurosci 30:15165-15174. Medline

Handwerker HO (2008) What is a polymodal nociceptor? J Pain 9:309-310. CrossRef Medline

Hargreaves K, Dubner R, Brown F, Flores C, Joris J (1988) A new and sensitive method for measuring thermal nociception in cutaneous hyperalgesia. Pain 32:77-88. CrossRef Medline

Hille B (1977) Local anesthetics: hydrophilic and hydrophobic pathways for the drug-receptor reaction. J Gen Physiol 69:497-515. CrossRef Medline

Jasmin L, Kohan L, Franssen M, Janni G, Goff JR (1998) The cold plate as a test of nociceptive behaviors: description and application to the study of chronic neuropathic and inflammatory pain models. Pain 75:367-382. CrossRef Medline

Ji RR, Befort K, Brenner GJ, Woolf CJ (2002) ERK MAP kinase activation in superficial spinal cord neurons induces prodynorphin and NK-1 upregulation and contributes to persistent inflammatory pain hypersensitivity. J Neurosci 22:478-485. Medline

Kistner K, Zimmermann K, Ehnert C, Reeh PW, Leffler A (2010) The tetrodotoxin-resistant $\mathrm{Na}+$ channel $\mathrm{Na}(\mathrm{v}) 1.8$ reduces the potency of local anesthetics in blocking C-fiber nociceptors. Pflugers Arch 459:751763. CrossRef Medline

Koerber HR, McIlwrath SL, Lawson JJ, Malin SA, Anderson CE, Jankowski MP, Davis BM (2010) Cutaneous C-polymodal fibers lacking TRPV1 are sensitized to heat following inflammation, but fail to drive heat hyperalgesia in the absence of TPV1 containing C-heat fibers. Mol Pain 6:58. CrossRef Medline

Kwan KY, Allchorne AJ, Vollrath MA, Christensen AP, Zhang DS, Woolf CJ, Corey DP (2006) TRPAl contributes to cold, mechanical, and chemical nociception but is not essential for hair-cell transduction. Neuron 50: 277-289. CrossRef Medline

Latremoliere A, Woolf CJ (2009) Central sensitization: a generator of pain hypersensitivity by central neural plasticity. J Pain 10:895-926. CrossRef Medline

Lawson JJ, McIlwrath SL, Woodbury CJ, Davis BM, Koerber HR (2008) TRPV1 unlike TRPV2 is restricted to a subset of mechanically insensitive cutaneous nociceptors responding to heat. J Pain 9:298-308. CrossRef Medline

Leffler A, Lattrell A, Kronewald S, Niedermirtl F, Nau C (2011) Activation of TRPAl by membrane permeable local anesthetics. Mol Pain 7:62. CrossRef Medline

Luis-Delgado OE, Barrot M, Rodeau JL, Schott G, Benbouzid M, Poisbeau P, Freund-Mercier MJ, Lasbennes F (2006) Calibrated forceps: a sensitive and reliable tool for pain and analgesia studies. J Pain 7:32-39. CrossRef Medline

Matsumoto M, Xie W, Ma L, Ueda H (2008) Pharmacological switch in Abeta-fiber stimulation-induced spinal transmission in mice with partial sciatic nerve injury. Mol Pain 4:25. CrossRef Medline

Mishra SK, Hoon MA (2010) Ablation of TrpV1 neurons reveals their selective role in thermal pain sensation. Mol Cell Neurosci 43:157-163. CrossRef Medline

Mishra SK, Tisel SM, Orestes P, Bhangoo SK, Hoon MA (2011) TRPV1lineage neurons are required for thermal sensation. EMBO J 30:582-593. CrossRef Medline

Perl ER (1996) Cutaneous polymodal receptors: characteristics and plasticity. Prog Brain Res 113:21-37. CrossRef Medline

Petsche U, Fleischer E, Lembeck F, Handwerker HO (1983) The effect of capsaicin application to a peripheral nerve on impulse conduction in 
functionally identified afferent nerve fibres. Brain Res 265:233-240. CrossRef Medline

Price TJ, Flores CM (2007) Critical evaluation of the colocalization between calcitonin gene-related peptide, substance $\mathrm{P}$, transient receptor potential vanilloid subfamily type 1 immunoreactivities, and isolectin B4 binding in primary afferent neurons of the rat and mouse. J Pain 8:263-272. CrossRef Medline

Ragsdale DS, McPhee JC, Scheuer T, Catterall WA (1994) Molecular determinants of state-dependent block of $\mathrm{Na}+$ channels by local anesthetics. Science 265:1724-1728. CrossRef Medline

Roberson DP, Binshtok AN, Blasl F, Bean BP, Woolf CJ (2011) Targeting of sodium channel blockers into nociceptors to produce long-duration analgesia: a systematic study and review. Br J Pharmacol 164:48-58. CrossRef Medline

Sándor Z, Varga A, Horváth P, Nagy B, Szolcsányi J (2005) Construction of a stable cell line uniformly expressing the rat TRPV1 receptor. Cell Mol Biol Lett 10:499-514. Medline

Scherrer G, Imamachi N, Cao YQ, Contet C, Mennicken F, O’Donnell D, Kieffer BL, Basbaum AI (2009) Dissociation of the opioid receptor mechanisms that control mechanical and heat pain. Cell 137:11481159. CrossRef Medline

Schmelz M (2011) Neuronal sensitivity of the skin. Eur J Dermatol 21 [Suppl 2]:43-47. Medline
Seal RP, Wang X, Guan Y, Raja SN, Woodbury CJ, Basbaum AI, Edwards RH (2009) Injury-induced mechanical hypersensitivity requires C-low threshold mechanoreceptors. Nature 462:651-655. CrossRef Medline

St Pierre M, Reeh PW, Zimmermann K (2009) Differential effects of TRPV channel block on polymodal activation of rat cutaneous nociceptors in vitro. Exp Brain Res 196:31-44. CrossRef Medline

Szolcsanyi J, Anton F, Reeh PW, Handwerker HO (1988) Selective excitation by capsaicin of mechano-heat sensitive nociceptors in rat skin. Brain Res 446:262-268. CrossRef Medline

Wang H, Woolf CJ (2005) Pain TRPs. Neuron 46:9-12. CrossRef Medline

Woodbury CJ, Zwick M, Wang S, Lawson JJ, Caterina MJ, Koltzenburg M, Albers KM, Koerber HR, Davis BM (2004) Nociceptors lacking TRPV1 and TRPV2 have normal heat responses. J Neurosci 24:6410 6415. CrossRef Medline

Woolf CJ, Ma Q (2007) Nociceptors-noxious stimulus detectors. Neuron 55:353-364. CrossRef Medline

Xie W, Matsumoto M, Chun J, Ueda H (2008) Involvement of LPA1 receptor signaling in the reorganization of spinal input through Abeta-fibers in mice with partial sciatic nerve injury. Mol Pain 4:46. CrossRef Medline

Zimmermann K, Leffler A, Fischer MM, Messlinger K, Nau C, Reeh PW (2005) The TRPV1/2/3 activator 2-aminoethoxydiphenyl borate sensitizes native nociceptive neurons to heat in wild-type but not TRPV1 deficient mice. Neuroscience 135:1277-1284. CrossRef Medline 